\title{
High $\mathrm{Zn} / \mathrm{Al}$ ratios enhance dehydrogenation vs hydrogen transfer reactions of Zn-ZSM-5 catalytic systems in methanol conversion to aromatics.
}

Irene Pinilla-Herrero $^{a, b, *}$, Elisa Borfecchia ${ }^{b, c}$, Uffe V. Mentzel $^{\text {b }}$, Finn Joensen ${ }^{\text {b }}$, Kirill

A. Lomachenko ${ }^{\text {}}$, Silvia Bordiga ${ }^{c}$, Carlo Lambertie,f ${ }^{\text {,f }}$, Gloria Berlier ${ }^{c}$, Unni Olsbye ${ }^{a}$, Stian Svelle ${ }^{\mathrm{a}, *}$, Pablo Beato ${ }^{\mathrm{b}, *}$

${ }^{a}$ Department of Chemistry, University of Oslo, Blindern, Oslo 0315, Norway

${ }^{b}$ Haldor Topsфe, Kgs. Lyngby 2800, Denmark

${ }^{c}$ Department of Chemistry, INSTM reference center and NIS interdepartmental center, University of Turin, Via Giuria 7, I-10135, Turin, Italy

${ }^{d}$ European Synchrotron Radiation Facility, 71 avenue des Martyrs, CS 40220, Grenoble Cedex 9, 38043 France

'IRC "Smart Materials”, Southern Federal University, Zorge str. 5, Rostov-on-Don, 344090 Russia

${ }^{f}$ Department of Physics and CrisDi interdepartmental center for crystallography, University of Turin, Via Giuria 1, I-10135, Turin, Italy

E-mails: i.p.herrero@kjemi.uio.no, elisa.borfecchia@unito.it, ufvm@ topsoe.com,

fj@topsoe.com, kirill.lomachenko@esrf.fr, silvia.bordiga@unito.it, carlo.lamberti@unito.it, gloria.berlier@unito.it, unni.olsbye@kjemi.uio.no, $\underline{\text { stian.svelle@kjemi.uio.no, pabb@topsoe.com }}$

Corresponding authors: Irene Pinilla-Herrero (i.p.herrero@kjemi.uio.no)

Stian Svelle (stian.svelle@ kjemi.uio.no)

Pablo Beato (pabb@ topsoe.com) 


\begin{abstract}
Two series of Zn-ZSM-5 catalysts were prepared by ion exchanging two commercial zeolites with different $\mathrm{Si} / \mathrm{Al}$ ratios (40 and 15) with increasing $\mathrm{Zn}$ loadings. The nature of the $\mathrm{Zn}$ sites in the zeolite was studied by spectroscopy using laboratory and synchrotron techniques. All the evidences suggest that catalytic activity is associated with $\left[\mathrm{Zn}\left(\mathrm{H}_{2} \mathrm{O}\right)_{\mathrm{n}}(\mathrm{OH})\right]^{+}$species located in the exchange positions of the materials with little or no contribution of $\mathrm{ZnO}$ or metallic $\mathrm{Zn}$. The effect of $\mathrm{Zn} / \mathrm{Al}$ ratio on their catalytic performance in methanol conversion to aromatics has been investigated. In all cases, higher $\mathrm{Zn}$ content causes an increase in the yield of aromatics while keeping the production of alkanes low. For similar $\mathrm{Zn}$ contents, high densities of $\mathrm{Al}$ sites favour the hydrogen transfer reactions and alkane formation whereas in samples with low $\mathrm{Al}$ contents, and thus higher $\mathrm{Zn} / \mathrm{Al}$ ratio, the dehydrogenation reactions in which molecular hydrogen is released are favoured.
\end{abstract}

Keywords: Zn-ZSM-5, Methanol to aromatics, Acidity, Zn sites 


\section{Introduction}

Light aromatic hydrocarbons, such as benzene, toluene and xylenes (BTX) are important intermediates in the petrochemical industry. They are commonly used as solvents and for the production of high-value secondary products such as plastics, paints, cosmetics or pharmaceuticals. BTX are traditionally obtained from naphtha via catalytic reforming or steam cracking with a global production in the range of 100 million metric tons per year that is projected to grow at a rate of 3.5-4\% in the next five years [1]. The increase in the global demand of aromatics together with the notion of finite crude oil reserves and the consequential necessity to implement an oil-independent economy makes it crucial to develop alternative processes for the production of BTX from non-petroleum sources. In this context, the possibility to directly convert methanol into aromatics (MTA) over zeolitic catalysts, that was described already 25 years ago $[2,3]$, is attracting a renewed interest from both industrial and academic researchers.

The methanol to aromatics reaction (MTA) falls into the general group of the so-called methanol to hydrocarbons (MTH) transformations, which allow obtaining fuels and chemicals avoiding the use of petroleum. MTH reactions have been widely investigated since their discovery by Mobil in 1976 [4]. The discovery attracted great attention due to the versatility of the process and the availability of methanol from rather abundant and diverse sources, such as coal and natural gas $[5,6]$, biomass or even $\mathrm{CO}_{2}[7,8]$. The MTH process involves multiple reaction steps within a quite complex mechanism, which has been intensively studied for decades [9-14]. Today, the dual cycle hydrocarbon pool mechanism is generally accepted [11]. According to this mechanism, the process is an autocatalytic reaction in which both alkene and aromatic molecules act as intermediates in two inter-related cycles involving many reactions such as methylation, cracking, 
hydride transfer, cyclization and dealkylation. Eventually, the reaction between the hydrocarbon intermediates and methanol molecules or the combination of hydrocarbons can lead to the formation of molecules that are too large to be able to diffuse through the zeolite pores and remain trapped within the framework, evolving to form carbonaceous deposits that are the responsible for the deactivation of the catalyst [15-20].

Initially, MTH technology was considered as a powerful alternative to oil-based routes for the production of gasoline compatible with the existing infrastructure. However, further investigations revealed that it is possible to selectively obtain practically any kind of hydrocarbons, including gasoline (MTG) light olefins (MTO), propylene (MTP) or aromatics (MTA), by modifying the catalysts and adjusting the operation conditions [21, 22]. Aromatization involves cyclization and hydrogen transfer reactions catalyzed by the Brønsted acid sites of the zeolite $[11,22,23]$. Olefins act as hydrogen acceptors in the bimolecular hydrogen transfer reaction, forming alkanes as hydrogen rich byproducts. In the case of MTA, the zeolite used as catalyst is partially doped with transition metals, forming a bifunctional system with Brønsted and Lewis acid sites from the zeolite and new metal Lewis sites. The goal of the incorporation of transition metals is to favour the aromatization reactions via additional dehydrogenation functionality. Recently, it has been reported that the hydrogen transfer may also be induced by methanol rather than by olefins, and not just Brønsted but also Lewis sites of the zeolite are proposed to be involved in the hydrogen transfer reactions for the formation of aromatics (and alkanes) [24]. This mechanism involves the presence of oxygenate intermediates such as formaldehyde. When transition metal ions are incorporated in the zeolitic catalyst, a new possibility appears, and the aromatization can take place at the metal Lewis acid sites by dehydrogenation instead of hydrogen transfer, thus forming molecular hydrogen as 
byproduct and keeping the production of alkanes low. This is interesting, first, because it means that a higher proportion of the carbon atoms from the reactants would be tuned into highly demanded products and, second, because of the intrinsic value of $\mathrm{H}_{2}$ as byproduct.

Several combinations of zeolites and transition metals have been investigated as MTA catalysts, with ZSM-5 being one of the most interesting topology in terms of stability and selectivity for the process, and $\mathrm{Zn}$ the metal that provides the highest yield of BTX products $[3,25-28]$. A full picture of the interplay between acid sites and metal sites is still missing, but it is known that the location of the metal sites (on the external crystal surface or within the micropores) and the nature of the sites formed have a great influence in the catalytic performance of the final material [28-32]. While only few contributions report the stabilization of unusual $\mathrm{Zn}^{+}$species in the zeolitic system [33], metallic $\mathrm{Zn}$, $\mathrm{ZnO}$ agglomerates or other $\mathrm{Zn}^{2+}$ species are generally proposed as the possible $\mathrm{Zn}$ sites formed in the zeolite. According to this proposal, two relatively close Al sites, and hence a quite low $\mathrm{Si} / \mathrm{Al}$ ratio, would be needed to stabilize the two positive charges of the exchanged cation. However, to compensate the negative charge generated by the presence of an isolated $\mathrm{Al}^{3+}$ in the inorganic framework, $\mathrm{Zn}^{2+}$ cations can also be incorporated as $\mathbf{Z}\left[\mathrm{Zn}^{2+}(\mathrm{OH})^{-}\right]^{+}$species [34], where $\mathbf{Z}$ indicates coordination to framework oxygens $\left(\mathrm{O}_{\mathrm{fw}}\right)$ in the proximity of one framework aluminium $\left(\mathrm{Al}_{\mathrm{fw}}\right)$ site. Again, depending on the elemental composition and the spatial distribution in the zeolite, such hydroxylated species are expected to undergo dehydration reactions at high temperature, and evolve into new $\mathrm{Zn}^{2+}$ species [31]. In samples with low $\mathrm{Zn}$ content and low $\mathrm{Si} / \mathrm{Al}$ ratio, monomeric $\mathbf{Z}_{2} \mathbf{Z n}^{2+}$ species are expected. On the other hand, at higher $\mathrm{Zn}$ loadings and 
intermediate $\mathrm{Si} / \mathrm{Al}$ ratio, two $\mathbf{Z}[\mathrm{Zn}(\mathrm{OH})]^{+}$species (with each $\mathrm{Zn}$ cation interacting with one $\mathrm{Al}$ site) might be able to form oxygen bridged $\mathrm{Zn}-\mathrm{O}-\mathrm{Zn}$ species.

Not surprisingly, the nature of the Zn sites strongly depends on the distribution of Al sites in the zeolite and hence on the exact preparation method $[28,35,36]$. Among the different proposed methods to incorporate $\mathrm{Zn}$ in the parent zeolite, ion exchange generally provides higher ratio of active cationic species promoting aromatization and dehydrogenation reactions [28]. It is important to note that the incorporation of $\mathrm{Zn}$ ions in the exchange positions effectively reduces the amount of Brønsted acid centers, which are also required in order to form the olefins that can undergo cyclization and aromatization reactions. An optimum elemental composition for high aromatization yields should therefore balance the amounts and nature of $\mathrm{Zn}$ species with respect to the Brønsted acid centers in the bifunctional material.

In this contribution, we aim to study exactly this balance between acid site distribution and $\mathrm{Zn}$ content and its effect on the aromatization activity of HZSM-5 zeolites. For this purpose, samples with increasing $\mathrm{Zn}$ loadings have been produced by ion exchange of two parent HZSM-5 zeolites with different $\mathrm{Si} / \mathrm{Al}$ ratios. In addition to detailed catalytic testing, the samples were characterized by X-ray diffraction (XRD) and $\mathrm{N}_{2}$-sorption in order to confirm their structural integrity and the accessibility of the micropores. Pyridine adsorption followed by transmission Fourier transform infrared (FTIR) spectroscopy [37] was applied to obtain information on the amount and distribution of acid sites and a combination of in situ and operando X-ray absorption spectroscopy (XAS) techniques [38] were used to characterize the nature of the $\mathrm{Zn}$ species formed during activation and MTA reaction. We show that, even though high yields of aromatics can be achieved over pure zeolites with a high density of Brønsted acid sites, the presence of $\mathrm{Zn}$ at relatively 
high $\mathrm{Si} / \mathrm{Al}$ ratio allows to force the aromatics formation mainly via the dehydrogenation pathway.

\section{Experimental}

\subsection{Preparation of the catalysts}

Two commercial ZSM-5 samples were used as raw materials: CBV-3024E ( $\mathrm{Si} / \mathrm{Al}=15)$ and CBV-8014 (Si/Al=40) obtained from Zeolyst International. Both samples were ionexchanged, first with a $\mathrm{NH}_{4} \mathrm{NO}_{3}$ solution $(98 \%)$ to have them in their ammonium form and, subsequently with excess of $\mathrm{Zn}\left(\mathrm{NO}_{3}\right)_{2} \cdot 6 \mathrm{H}_{2} \mathrm{O}\left(36.6 \mathrm{~g}\right.$ in $1000 \mathrm{~mL}$ demineralised- $\left.\mathrm{H}_{2} \mathrm{O}\right)$, one, two or three times, respectively, at $80{ }^{\circ} \mathrm{C}$ for one hour in order to produce a set of 8 samples with different acidity and Zn loadings. After each exchange, the samples were filtered and washed with water at $80{ }^{\circ} \mathrm{C}$ and dried at $110{ }^{\circ} \mathrm{C}$ overnight. In a last step, the materials were calcined at $450{ }^{\circ} \mathrm{C}$ for 2 hours. Details on the composition of the samples are collected in Table 1.

Table 1. Experimental details of the $\mathrm{Zn}$ incorporation in two parent ZSM-5 zeolites with different $\mathrm{Si} / \mathrm{Al}$ ratios.

\begin{tabular}{|c|c|c|c|c|}
\hline Sample & $\begin{array}{l}\text { Parent } \\
\text { zeolite }\end{array}$ & $\mathbf{S i} / \mathbf{A l}$ & $\begin{array}{ll}\text { Number } \\
\text { exchanges }\end{array}$ & Zn content $(\%)$ \\
\hline Si/Al15-P & & & 0 & 0.0 \\
\hline Si/Al15-1Zn & & & 1 & 1.3 \\
\hline Si/Al15-2Zn & $C B V-3024 E$ & 15 & 2 & 1.7 \\
\hline Si/Al15-3Zn & & & 3 & 1.9 \\
\hline Si/Al40-P & & & 0 & 0.0 \\
\hline Si/Al40-1Zn & CRV 8014 & 40 & 1 & 0.7 \\
\hline Si/Al40-2Zn & CBV-8014 & 40 & 2 & 1.0 \\
\hline Si/Al40-3Zn & & & 3 & 1.0 \\
\hline
\end{tabular}


Parent samples are named as Si/AlX-P, where "X" indicates the Si/Al ratio of each material, and exchanged materials are named as: Si/AlX-YZn, with "Y" denoting the number of Zn-exchanges.

\subsection{Catalysts characterization}

\subsubsection{Laboratory characterization}

Powder X-ray diffraction (XRD) patterns of the catalysts were recorded using a Siemens Bruker D5000 instrument with Bragg-Brentano geometry and $\mathrm{CuK} \alpha$ radiation $(\lambda=$ 1.5406). Samples were measured using flat sample holders loaded with $25 \mathrm{mg}$ of powder. The chemical composition of the samples ( $\mathrm{Si}, \mathrm{Al}$ and $\mathrm{Zn}$ content) was analyzed by inductively coupled plasma optical emission spectrometry (ICP-OES) using an Agilent 720 instrument.

Adsorption capacity and textural properties of the catalysts were evaluated by $\mathrm{N}_{2}$ adsorption-desorption measurements carried out at $-196{ }^{\circ} \mathrm{C}$ on a Bel Belsorp-mini II apparatus. Prior to the measurements, the samples were degassed under vacuum for 4 hours, at $80{ }^{\circ} \mathrm{C}$ the first hour and then at $300{ }^{\circ} \mathrm{C}$. The BET equation and t-plot method were used to calculate the surface area, external area and micropore volume respectively $[39,40]$. Crystal sizes and morphology were studied by scanning electron microscopy (SEM), recording the images on a Hitachi Su 8230 FE-SERM working at 5-10 kV with beam acceleration mode at distances around $10 \mathrm{~mm}$.

Fourier-transform infrared spectroscopy (FTIR) experiments were performed in transmittance on a Bruker Vertex 80 instrument with a Mercury Cadmium Telluride (MCT) detector using a resolution of $2 \mathrm{~cm}^{-1}$. Before dosing probe molecules, $(\mathrm{CO}$ at $196{ }^{\circ} \mathrm{C}$ and pyridine at room temperature) the samples were pretreated under vacuum 
$\left(<10^{-5} \mathrm{mbar}\right)$ following a temperature $\operatorname{ramp}\left(3{ }^{\circ} \mathrm{C} / \mathrm{min}\right)$ till the set point of $450{ }^{\circ} \mathrm{C}$, which was maintained for 1 hour. Pyridine saturated samples were outgassed at $200{ }^{\circ} \mathrm{C}$, to remove excess and physisorbed pyridine. Brønsted and Lewis sites were quantified based on the integrated intensity of the bands at 1544 and $1455 \mathrm{~cm}^{-1}$, respectively using the integrated molar extinction coefficient reported in previous literature [41].

\subsubsection{Operando XAS}

operando XAS data were collected at the BM23 beamline [42] of the European Synchrotron Radiation Facility (ESRF, Grenoble, France). To keep the Zn-ZSM-5 catalysts under controlled conditions in terms of temperature and gas feed during XAS acquisitions, a setup based on the Microtomo reactor cell [43] designed by the ESRF Sample Environment Group was employed. The gas feed and reaction products formed during the XAS measurements were qualitatively monitored by a mass spectrometer (MS) connected to the outlet of the cell.

XAS spectra were initially collected for the as-prepared hydrated catalysts at room temperature (RT) in air. Subsequently, the samples, held inside the Microtomo reactor cell, were pretreated heating in technical air $(20 \mathrm{ml} / \mathrm{min})$ from $\mathrm{RT}$ to $500{ }^{\circ} \mathrm{C}$ (heat ramp: $5{ }^{\circ} \mathrm{C} / \mathrm{min}$ ) and kept at $500{ }^{\circ} \mathrm{C}$ for $30 \mathrm{~min}$. The temperature was subsequently lowered to $420{ }^{\circ} \mathrm{C}$, and the XAS spectra of the activated catalysts were collected. Finally, while keeping the catalysts at $420{ }^{\circ} \mathrm{C}$, the gas feed was switched to methanol $(\mathrm{MeOH}) / \mathrm{He}$, by passing a $20 \mathrm{ml} \mathrm{He}$ flow through a saturator filled with $\mathrm{MeOH}$ at $17^{\circ} \mathrm{C}$. The XAS spectra in MTA conditions were collected after a stable MS signal from toluene was detected. Zn K-edge XAS data were collected in transmission mode, using a double-crystal Si(111) monochromator for the incident energy scan, two Rh-coated mirrors at $5 \mathrm{mrad}$ angle for harmonics rejection, and ionization chambers for the detection of incident $\left(\mathrm{I}_{0}\right)$ and 
transmitted $\left(\mathrm{I}_{1}\right)$ photons. For energy calibration, $\mathrm{Zn}$ metal foil was measured simultaneously with all the acquired spectra using a third ionization chamber $\mathrm{I}_{2}$ [44]. The Zn-ZSM-5 catalysts were measured in the form of a self-supporting pellets, fixed inside the reactor cell. The optimized pellet weights were in the $150-170 \mathrm{mg}$ range for $1.3 \mathrm{~cm}^{2}$ area pellets, resulting in edge jumps $\Delta \mu \mathrm{x}$ in the $0.2-0.4$ range (depending on $\mathrm{Zn}$-loading) for a total absorption after the edge of $\mu \mathrm{x}=2.55$.

For each catalyst state (hydrated, pretreated, and during MTA reaction), we acquired a series of consecutive XAS scans of $~ 30$ min each, collected from 9470 to $10635 \mathrm{eV}$ (up to $\sim 16 \AA^{-1}$ ) with $\mathrm{k}$-space sampling $\Delta \mathrm{k}=0.035 \AA^{-1}$ and acquisition time in the EXAFS region quadratically increasing with $\mathrm{k}$ from 1 to 4 s/point to improve the signal-to-noise ratio at higher k-values. The final XAS spectra were obtained by averaging the $\mu(\mathrm{E})$ curves corresponding to the consecutive scans (two or four for high-loading and lowloading samples, respectively), after checking reproducibility among the acquisitions [45]. A faster XANES acquisition mode (ca. $6 \mathrm{~min} / \mathrm{scan}$ ) collected in a shorter energy range (9470-10407 eV) was employed to check the evolution of the XAS features during heating/cooling ramps and stabilization at steady conditions.

Three relevant reference samples; a $50 \mathrm{mM}$ aqueous solution of $\mathrm{Zn}\left(\mathrm{NO}_{3}\right)_{2}$ : a $\mathrm{Zn}$ metal foil; and a $\mathrm{ZnO}$ powder were also measured at $\mathrm{RT}$ in air, using the same acquisition mode as described above.

XAS spectra of the Zn-ZSM-5 and the reference materials were aligned in energy employing the corresponding $\mathrm{Zn}$ metal foil spectra detected by the $\mathrm{I}_{2}$ ionization chamber and normalized to unity edge jump using the Athena software from the Demeter package [46]. The $\chi(\mathrm{k})$ functions extracted using the Athena program and R-space EXAFS spectra 
were obtained by calculating the Fourier transform of the $\mathrm{k}^{2} \chi(\mathrm{k})$ functions in the $(2.5-$ 12.5) $\AA^{-1}$ k-range.

\subsubsection{DFT-assisted EXAFS fitting}

DFT-assisted EXAFS fitting is an approach that has shown its potential for cases of a complex local environments around the adsorbing atom [47, 48]. The structure of $\mathbf{Z}[\mathrm{Zn}(\mathrm{OH})]$ species used as starting point for EXAFS fitting was obtained by means of DFT geometry optimization. As a starting point, a cluster containing a complex of two 10Rs with the corresponding eight 5Rs was cut out from the bulk structure of ZSM-5 taken from IZA-SC Database of Zeolite Structures [49]. To eliminate dangling bonds, outer oxygen atoms were terminated by hydrogens.

Geometry optimization was carried out with the ADF2014 software [50]. Slater-type basis sets were employed for all atoms: TZ2P for the $\mathrm{Zn}(\mathrm{OH})$ group, TZP for $\mathrm{Si}, \mathrm{Al}$ and $\mathrm{O}$ atoms, and DZP for terminal $\mathrm{OH}$ groups. To speed up the calculations, the frozen core approximation (up to $2 \mathrm{p}$ frozen for $\mathrm{Zn}, \mathrm{Si}$ and $\mathrm{Al}, 1 \mathrm{~s}$ frozen for $\mathrm{O}$ ) was used [51]. In order to account for exchange correlation effects, the dispersion corrected PBE-D3-BJ functional was chosen [52]. Relativistic effects were dealt with by means of the scalar ZORA approximation [53]. Convergence criteria were set to 0.001 Hartree, 0.001 Hartree/ $\AA$ and $0.01 \AA$ for energy, gradients and bond distances respectively.

Geometry optimization was performed in three steps, the first two involving a purely siliceous cluster. First, only terminal hydrogens were relaxed, while $\mathrm{Si}$ and $\mathrm{O}$ atoms were kept fixed. Then, the hydrogens together with the adjacent $\mathrm{O}$ atoms were frozen, while the rest of the cluster was optimized. Finally, one Si atom at the T12 position [54] was substituted by $\mathrm{Al}$, and the $\mathrm{ZnOH}$ group was placed in its vicinity above the $5 \mathrm{R}$. The 
optimization was performed keeping the terminal $\mathrm{OH}$ groups fixed, while all the other atoms could move without any symmetry restrictions.

EXAFS fitting was performed in $\mathrm{R}$-space in the $\Delta \mathrm{R}=1.0-3.3 \AA$ range, on the FT of the $\mathrm{k}^{2}$-weigthed $\chi(\mathrm{k})$ EXAFS spectra performed in the $2.5-11.0 \AA^{-1}$ range, resulting in 17 independent points $(2 \Delta \mathrm{k} \Delta \mathrm{R} / \pi>17)$. Phases and amplitudes have been calculated by FEFF6 code [55, 56] using the Arthemis software from the Demeter package [46], employing the DFT-optimized structure of $\mathbf{Z}[\mathrm{Zn}(\mathrm{OH})]$ as input.

The fitting model included all the single-scattering (SS) paths present in the R-range of interest, representing the dominant contribution to the experimental EXAFS signal. To limit the number of optimized variables, all the SS paths have been optimized with the same passive amplitude reduction factor $\left(\mathrm{S}_{0}{ }^{2}\right)$ and with the same energy shift parameter $(\Delta \mathrm{E})$. In the EXAFS refinement, coordination numbers $\mathrm{N}_{\mathrm{i}}$ for each of the considered coordination shells were fixed to the DFT values. In the first shell region, the adopted fitting model included the SS path including an extra-framework oxygen atom from the $\mathrm{OH}$ group $\left(\mathrm{O}_{\mathrm{ef}}, \mathrm{N}_{\mathrm{O}(\mathrm{ef})}=1\right.$, parametrized with independent radial shift $\Delta \mathrm{R}_{\mathrm{O}(\mathrm{ef})}$ and DebyeWaller parameter $\left.\sigma_{\mathrm{O}(\mathrm{ef})}^{2}\right)$ and two subshells of framework oxygen atoms $\left(\mathrm{O}_{\mathrm{fw}}, \mathrm{N}_{\mathrm{O}(\mathrm{fw})}=1\right.$ and $\mathrm{O}_{\mathrm{fw}}^{\prime}, \mathrm{N}_{\mathrm{O}}{ }^{\prime}(\mathrm{fw})=2$, parametrized each with an independent radial shift parameter, namely $\Delta \mathrm{R}_{\mathrm{O}(\mathrm{fw})}$ and $\Delta \mathrm{R}_{\mathrm{O}^{\prime}(\mathrm{fw})}$, but with a common $\left.\mathrm{DW} \sigma^{2} \mathrm{O(fw)}\right)$. In the second shell region, the fitting model includes the SS paths involving the nearest $\mathrm{Al}$ neighbor (at $2.97 \AA$ from $\mathrm{Zn}$ according to DFT), parameterized with an independent radial shift $\left(\Delta \mathrm{R}_{\mathrm{T}}\right)$ and $\mathrm{DW}$ factor $\left(\sigma^{2} \mathrm{~T}\right)$. Finally, a lower-level parametrization strategy has been adopted for the SS paths which involve the farthermost Si and O atoms of the ZSM-5 framework (3.1 -3.3 $\AA ̊$ distance range from the $\mathrm{Zn}$ center), providing a minor but not negligible contribution 
to EXAFS signal. These SS paths were modelled considering a common contraction/expansion factor $\alpha_{\mathrm{fw}}$ and DW factor $\sigma_{\mathrm{fw}}^{2}$ increasing as the square root of the distance $R_{\text {eff,i }}$ of the $i^{\text {th }}$ scattering atom from the absorber $\left(\Delta R_{f w, i}=\alpha_{f w} R_{e f f, i}, \sigma_{f w, i}^{2}=s s_{f w}\right.$

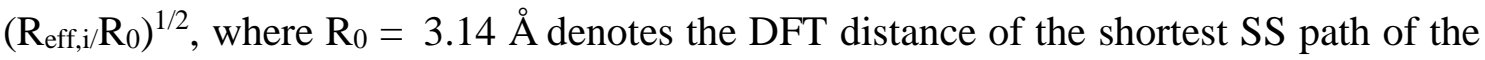
group). This approach is effective in considering a larger number of scattering paths, while limiting both the number of optimized parameters and the correlation among them, as already demonstrated in several cases $[57,58]$.

\subsection{Catalytic testing}

The catalytic tests were performed with $50 \mathrm{mg}$ of catalyst (sieve fraction $250-420 \mu \mathrm{m}$ ) in a fixed bed reactor operated at atmospheric pressure and at $400{ }^{\circ} \mathrm{C}$, using a straight tubular quartz reactor with $4 \mathrm{~mm}$ inner diameter. A temperature couple enclosed within a quartz sheath was located inside the reactor, in contact with the catalyst bed to monitor the reaction temperature. Prior to testing, all samples were pretreated in situ at $550{ }^{\circ} \mathrm{C}$ under oxygen flow for an hour to remove traces of adsorbed hydrocarbons and water. Methanol was fed by flowing $\mathrm{He}(15 \mathrm{ml} / \mathrm{min})$ through a saturator at $20^{\circ} \mathrm{C}$ to obtain a partial pressure of methanol of 130 mbar, which results in a weight hourly space velocity (WHSV) of 3 $\mathrm{h}^{-1}$. The reactor effluent stream was analyzed on-line by gas chromatography using an Agilent 6890 A instrument equipped with a flame ionization detector (FID) and a Supelco SPB-5 capillary column with dimensions of $60 \mathrm{~m} \times 0.53 \mathrm{~mm} \times 3 \mu \mathrm{m}$.

\section{Results}

\subsection{Physico-chemical characterization: composition, morphology, porosity}


The X-ray diffraction confirms that both the parent and exchanged samples exhibit only the characteristic diffraction peaks of MFI topology (Fig. 1). No substantial loss in the intensity of the diffraction peaks was detected in the series of samples with $\mathrm{Si} / \mathrm{Al}=40$ after the ion exchange. However, a slight decrease is observed in the exchanged samples produced from the $\mathrm{ZSM}-5$ with higher density of acid sites $(\mathrm{Si} / \mathrm{Al}=15)$ when $\mathrm{Zn}$ is incorporated.

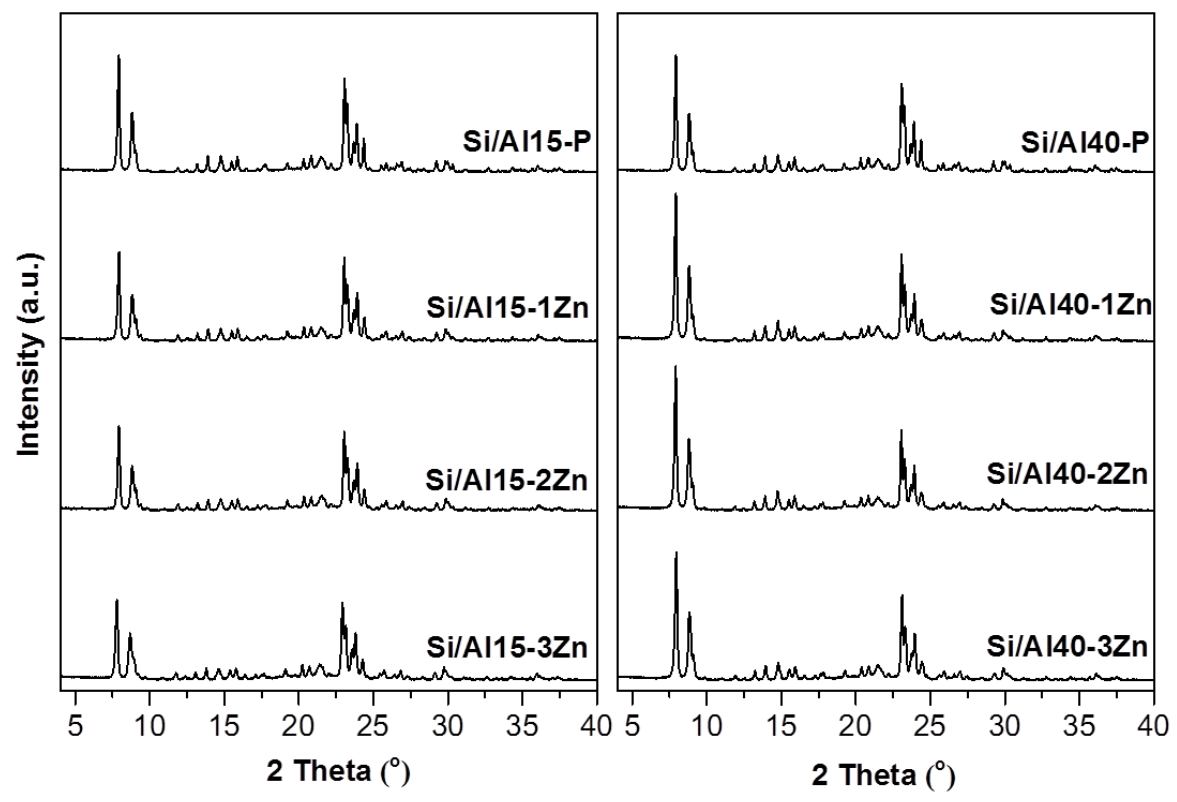

Fig. 1. Powder X-ray diffraction patterns of the parent H-ZSM-5 and the Zn-containing HZSM5 zeolites.

The amount of $\mathrm{Zn}$ in the ZSM-5 zeolites and the overall chemical composition of the calcined samples were determined by ICP-OES analysis (Table 2). We observe that the incorporation of $\mathrm{Zn}$ is favoured in the parent zeolite with $\mathrm{Si} / \mathrm{Al}=15$, which has a higher density of Brønsted acid sites. In addition, for this zeolite, the incorporation of $\mathrm{Zn}$ increases progressively with further ion exchange treatments, whereas the $\mathrm{Zn}$ content 
remains rather constant in the $\mathrm{Si} / \mathrm{Al}=40$ series. This observation is in good agreement with the previous literature describing that it is more likely to stabilize higher amounts of metal in exchange positions in zeolites with higher density of acid sites because of the higher probability of having two $\mathrm{Al}$ sites close enough to stabilize isolated $\mathrm{Zn}^{2+}$ ions [34]. However, considering the lower $\mathrm{Al}$ content in the $\mathrm{Si} / \mathrm{Al}=40$ material, the $\mathrm{Zn} / \mathrm{Al}$ ratio is higher in that series of samples.

Table 2. Elemental composition of the samples measured by ICP and density of acid sites detected from the FTIR experiments using pyridine as probe molecule.

\begin{tabular}{|c|c|c|c|c|c|c|c|}
\hline \multirow[t]{2}{*}{ Sample } & \multicolumn{4}{|c|}{ Elemental composition $(\mathrm{mmol} / \mathrm{g})$} & \multicolumn{3}{|c|}{$\begin{array}{l}\text { Density of acid sites } \\
\text { (mmol/g) }\end{array}$} \\
\hline & Al & $\mathbf{S i}$ & $\mathbf{Z n}$ & $\mathbf{Z n} / \mathbf{A l}$ & Brønsted (B) & Lewis (L) & $B / L$ \\
\hline Si/Al15-P & 0.83 & 13.64 & 0.00 & 0.00 & 0.91 & 0.34 & 2.68 \\
\hline Si/Al15-1Zn & 0.95 & 15.28 & 0.19 & 0.20 & 0.27 & 1.10 & 0.25 \\
\hline Si/Al15-2Zn & 0.94 & 15.28 & 0.26 & 0.28 & 0.18 & 1.12 & 0.16 \\
\hline Si/Al15-3Zn & 0.92 & 15.13 & 0.29 & 0.32 & 0.20 & 1.50 & 0.13 \\
\hline Si/Al40-P & 0.35 & 13.96 & 0.00 & 0.00 & 0.31 & 0.12 & 2.58 \\
\hline Si/Al40-1Zn & 0.46 & 18.52 & 0.11 & 0.24 & 0.24 & 0.45 & 0.53 \\
\hline Si/Al40-2Zn & 0.37 & 15.75 & 0.15 & 0.41 & 0.18 & 0.62 & 0.29 \\
\hline Si/Al40-3Zn & 0.36 & 15.52 & 0.16 & 0.44 & 0.17 & 0.70 & 0.24 \\
\hline
\end{tabular}

Scanning electron microscopy (SEM) reveals significant differences in crystal size and morphology for the two parent zeolites (Fig. S1). The materials with $\mathrm{Si} / \mathrm{Al}=40$ are formed by agglomerated small crystals, whereas smaller crystallites forming larger agglomerates are observed in the samples with $\mathrm{Si} / \mathrm{Al}=15$. This might influence the diffusion capacity of the samples and should be kept in mind when analysing the adsorption capacity of the different materials. No significant variations in either agglomeration and crystal size or shape were seen for the exchanged samples.

The presence of metal ions in the channels of the zeolites could cause some spatial restrictions. To identify if the presence of $\mathrm{Zn}$ in the micropores of the zeolites is altering 
the adsorption capacity or the textural properties of the samples, all the parent and exchanged materials were studied by $\mathrm{N}_{2}$ physisorption measurements. Surface areas and pore volumes are collected in Table 3. These characteristics remain constant with the incorporation of $\mathrm{Zn}$. Thus, there is no indication of diffusion restrictions for the zeolitic materials due to the presence of $\mathrm{Zn}$ ions (Table 3). All the isotherms are close to type I (according to the IUPAC classification), which is associated to microporous materials [39]. However, small non-microporous contributions are also revealed, as shown by the increasing nitrogen uptake at relatively high partial pressures (Fig. S2). This contribution is higher in all the samples generated from the parent with $\mathrm{Si} / \mathrm{Al}=15$, and likely due to filling of interparticle spaces formed in the agglomerates which are in the meso/macropore range (Table 3).

Table 3. Adsorption capacity and textural properties of the parent and Zn-exchanged ZSM-5 samples*.

\begin{tabular}{lccccccc}
\hline \multirow{2}{*}{ Sample } & \multicolumn{3}{c}{ Surface area $\left(\mathbf{m}^{2} / \mathbf{g}\right)$} & & \multicolumn{3}{c}{ Pore volume $\left(\mathbf{c m}^{3} / \mathbf{g}\right)$} \\
\cline { 2 - 4 } \cline { 6 - 8 } & BET & NonMicrop & Microp & & Total & NonMicrop & Microp \\
\hline Si/Al15-P & 439 & 34 & 405 & & 0.37 & 0.19 & 0.18 \\
Si/Al15-1Zn & 403 & 36 & 367 & & 0.36 & 0.20 & 0.16 \\
Si/Al15-2Zn & 401 & 36 & 365 & & 0.37 & 0.21 & 0.16 \\
Si/Al15-3Zn & 409 & 37 & 372 & & 0.37 & 0.20 & 0.17 \\
\hline Si/Al40-P & 434 & 29 & 405 & & 0.33 & 0.14 & 0.19 \\
Si/Al40-1Zn & 445 & 21 & 424 & & 0.29 & 0.08 & 0.21 \\
Si/Al40-2Zn & 449 & 17 & 432 & & 0.29 & 0.08 & 0.21 \\
Si/Al40-3Zn & 415 & 16 & 399 & & 0.27 & 0.08 & 0.19 \\
\hline
\end{tabular}

* The standard error of the calculated surface areas and pore volumes of the materials are estimated to be 4 and $5 \%$ respectively.

\subsection{Identification of $\mathrm{Zn}$ species in $\mathrm{Zn}-\mathrm{ZSM}-5$}

\subsubsection{FTIR analysis of acidic properties}


To investigate how the incorporation of $\mathrm{Zn}$ in the zeolite alters the distribution and nature of the reactive sites in the material, samples were characterized by FTIR using pyridine and $\mathrm{CO}$ as probe molecules.

Fig. 2.a shows the FTIR spectra of the activated samples in the range of the $\mathrm{O}-\mathrm{H}$ stretching vibrations before pyridine absorption. The band at $3610 \mathrm{~cm}^{-1}$ is assigned to Brønsted acid sites [Si-(OH)-Al], while the band at $3745 \mathrm{~cm}^{-1}$ is related to isolated silanols [Si-OH], typically located at the external surface. The shoulder towards lower frequencies $(\sim 3728$ $\mathrm{cm}^{-1}$ ) has been assigned to weakly interacting internal silanols. This contribution becomes slightly more important in samples with $\mathrm{Zn}$ of the $\mathrm{Si} / \mathrm{Al}=40$ series. Finally, for all samples of the $\mathrm{Si} / \mathrm{Al}=15$ series an additional weak band located at $\sim 3664 \mathrm{~cm}^{-1}$ is observable, which is assigned to extra-framework aluminium (EFAl) species $[59,60]$. This band is also more intense in samples with $\mathrm{Zn}$.

After chemisorption of pyridine, the corresponding ring vibrational modes of the molecule appear in the spectra (Fig. 2b). All the Brønsted sites in the materials are accessible to pyridine, as the band associated to the $\mathrm{OH}$ stretching vibrations of Brønsted sites $\left(3610 \mathrm{~cm}^{-1}\right)$ is completely extinguished after pyridine is dosed (Fig. S3). The total amount of adsorbed pyridine molecules on Brønsted and Lewis acid sites is calculated from the integral areas of the two characteristic bands (1544 and $1455 \mathrm{~cm}^{-1}$ respectively), and the values are collected in Table 2 .

We observe that the incorporation of $\mathrm{Zn}$ in the parent zeolites causes an increase in the density of Lewis acid sites together with a decrease in the density of Brønsted sites. This is expected since the incorporation of $\mathrm{Zn}$ in a zeolite framework replaces the charge balancing species, effectively reducing the concentration of Brønsted acid sites and 
giving rise to new Lewis sites [28]. Importantly, from the calculated densities of Brønsted and Lewis sites it is clear that more Lewis sites are formed than the number of Brønsted sites consumed. This point will be elaborated in the discussion.
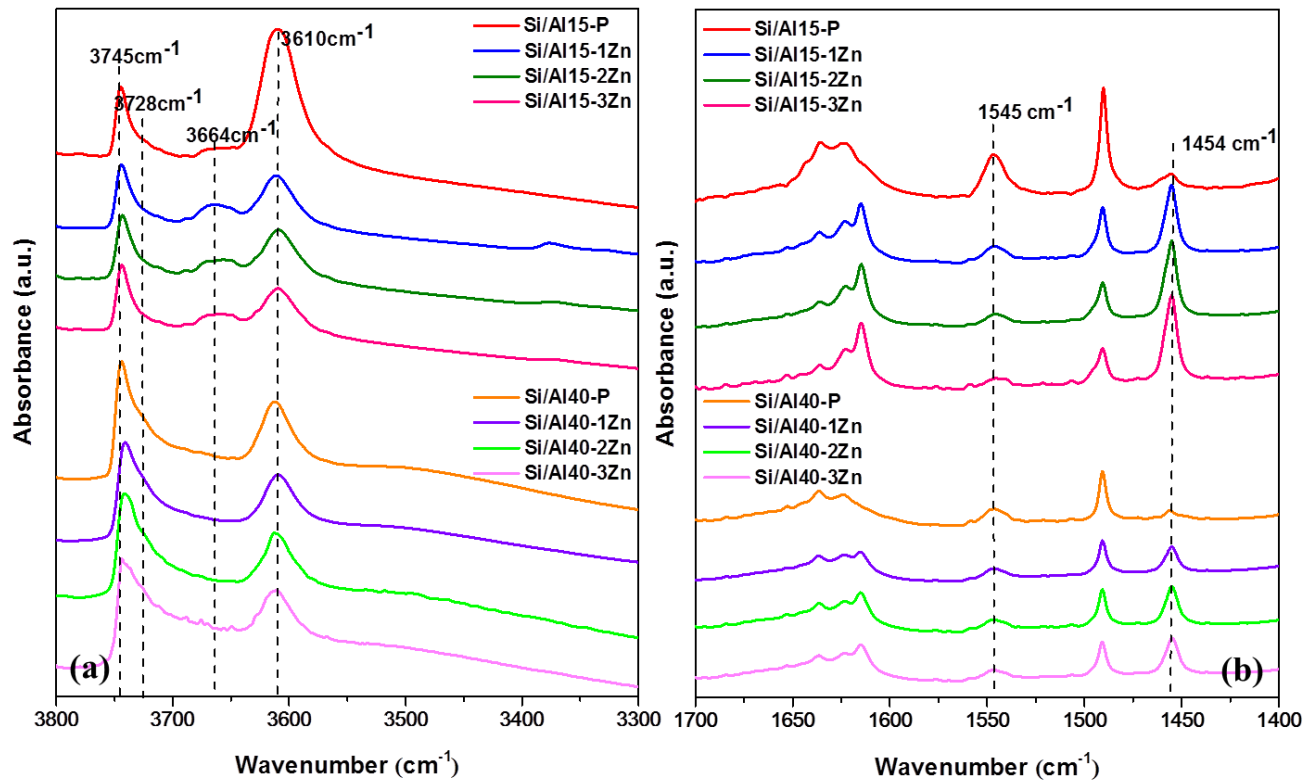

Fig. 2. FTIR spectra of the parent H-ZSM-5 and the Zn-containing HZSM-5 zeolites. a) FTIR spectra of the pre-treated samples in the $\mathrm{OH}$ stretching region. b) FTIR spectra of pyridine adsorbed on the zeolites.

Further insights about this result can be obtained by using $\mathrm{CO}$ as a probe molecule. Fig. 3 reports background subtracted spectra at low CO coverage. In both parent zeolites, the typical band related to $\mathrm{CO}$ interacting with $[\mathrm{Si}-(\mathrm{OH})-\mathrm{Al}]$ at $2174 \mathrm{~cm}^{-1}$ are present together with weak components at 2230 and $2214 \mathrm{~cm}^{-1}$, assigned to $\mathrm{CO}$ on EFAl sites with different Lewis character [61]. After $\mathrm{Zn}$ insertion, bands in the Lewis sites region (2250 $-2200 \mathrm{~cm}^{-1}$ ) grow substantially, and at least one new component is observed at $2224 \mathrm{~cm}^{-}$ 1. This is more evident on the samples with $\mathrm{Si} / \mathrm{Al}=15$, in agreement with the almost double Lewis site concentration measured by pyridine adsorption (Table 2). The new 
band can be safely assigned to $\mathrm{Zn}^{2+}$ ions, in agreement with the reports by Kazansky et al. [62]. These results indicate that pyridine probes both $\mathrm{Zn}^{2+}$ and EFAl sites.
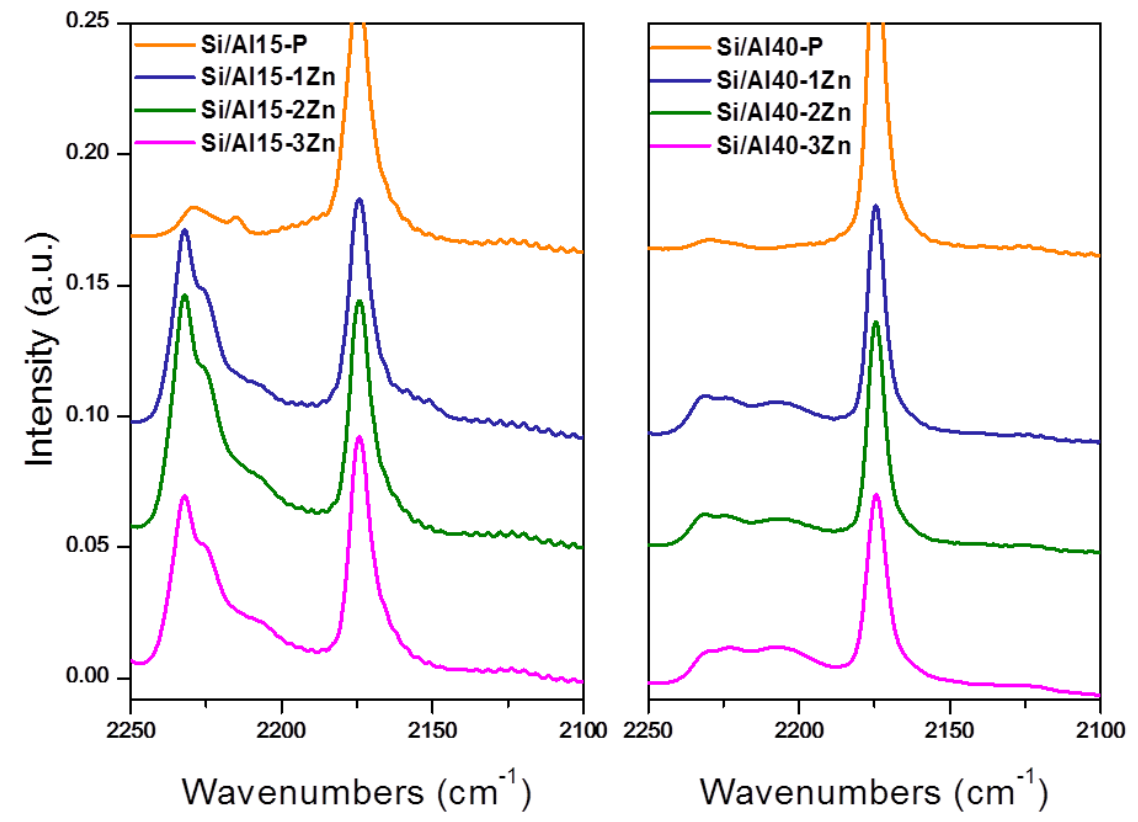

Fig. 3. Background-subtracted FTIR spectra of $\mathrm{CO}(0.1 \mathrm{mbar})$ adsorbed at $-196{ }^{\circ} \mathrm{C}$ on parent $\mathrm{H}-$ ZSM-5 and Zn-containing HZSM-5 zeolites.

\subsubsection{XAS analysis of Zn speciation in the as-prepared and pretreated catalysts and under}

\section{MTA conditions}

To obtain further information on the nature of $\mathrm{Zn}$ sites in Zn-ZSM-5 catalysts at key process conditions, selected samples were characterized by Zn K-edge X-ray absorption spectroscopy (XAS). Fig. 4 shows the XANES and FT-EXAFS spectra for a Zn-ZSM-5 catalyst (Si/Al40-3Zn) in its hydrated state (RT in air), after pretreatment in air at $500{ }^{\circ} \mathrm{C}$ and cooling down to MTA operation temperature of $420{ }^{\circ} \mathrm{C}$, and finally under MTA conditions. For comparison, the figure also reports the XAS spectra of $\mathrm{Zn}\left(\mathrm{NO}_{3}\right)_{2}$ aqueous solution, representative of fully hydrated $\mathrm{Zn}^{2+}$ ions, $\mathrm{Zn}$ metal and $\mathrm{ZnO}$ powder. These 
will guide the interpretation of the XAS features observed for the investigated Zn-ZSM5 catalysts.

In the hydrated state at RT, the Zn species in the zeolite are almost indistinguishable from those observed in solution $[63,64]$, consisting of mobile $\left[\mathrm{Zn}\left(\mathrm{H}_{2} \mathrm{O}\right)_{\mathrm{n}}\right]^{2+}$ or $\left[\mathrm{Zn}^{2+}\left(\mathrm{H}_{2} \mathrm{O}\right)_{n-}\right.$ $\left.{ }_{1}(\mathrm{OH})\right]^{+}$complexes with $\mathrm{n}=6,5$. Also, no trace of aggregated phases in the form of welldefined metal or oxide particles can be found, as it is clear from the comparison with the respective reference compounds.
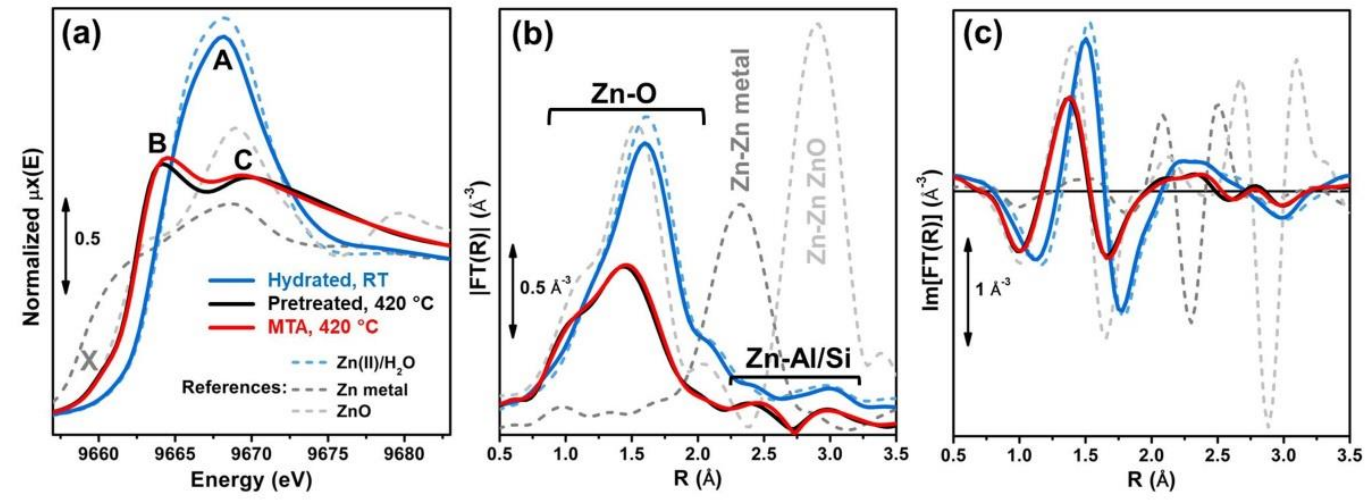

Fig. 4. Typical XAS fingerprints of Zn sites in Zn-ZSM-5 at key process steps. (a) Zn K-edge XANES for a representative Zn-ZSM-5 sample (Si/A140-3Zn) in the hydrated state at RT, after pretreatment in air at $500{ }^{\circ} \mathrm{C}$ and cooling to $420{ }^{\circ} \mathrm{C}$ and during MTA at the same temperature. For comparison, the XANES spectra for a series of reference compounds (measured at RT) are also reported, i.e. $\mathrm{Zn}\left(\mathrm{NO}_{3}{ }^{-}\right)_{2}$ aqueous solution, representative of fully hydrated $\mathrm{Zn}^{2+}$ ions, $\mathrm{Zn}$ metal foil and $\mathrm{ZnO}$. (b, c) Magnitude (b) and imaginary part (c) of the FT-EXAFS spectra for the same sample and reference compounds reported in part (a), using the same colour code. All the FTEXAFS spectra have been obtained by transforming the $\mathrm{k}^{2} \chi(\mathrm{k})$ EXAFS functions in the $2.5-12.5$ $\AA^{-1}$ range.

High-temperature activation in air results in a decreased intensity of the first-shell EXAFS peak, indicating a lower coordination number to O neighbours. Simultaneously, this peak 
shifts to a significantly shorter distance with respect to the hydrated state, comparable to that observed for the $\mathrm{ZnO}$ reference. Also, the absorption edge position, found at 9662.6 $\mathrm{eV}$ (first maximum in the derivative spectrum, Fig. S4) in the activated catalyst significantly shifts to lower energies with respect to the hydrated material $(9663.8 \mathrm{eV})$, approaching $\mathrm{ZnO}(9661.8 \mathrm{eV})$. However, the overall shape of the XANES spectrum is markedly different with respect to the $\mathrm{ZnO}$ reference. This sample has well-defined postedge peaks at ca. $9664.1 \mathrm{eV}$ (feature B) and $9669.8 \mathrm{eV}$ (feature C) and no trace of the characteristic $\mathrm{ZnO}$ resonance at $9679.7 \mathrm{eV}$.

The characteristic XANES features of the activated material are in line with previous reports on Zn-zeolites [31, 65, 66] and Zn-enzymes [67-69]. The average coordination geometry for Zn-sites in activated Zn-ZSM-5 is hence expected to be still pseudotetrahedral, but significantly distorted. The EXAFS signature of the first-shell is rather broad, suggesting the presence of multiple $\mathrm{Zn}-\mathrm{O}$ subshells at significantly different distances. In contrast to the hydrated sample, after pre-treatment we observe the presence of two additional well-defined maxima in the FT-EXAFS at ca. 2.4 and $3.0 \AA$ in the phaseuncorrected spectra, which we attribute to $\mathrm{Zn}-\mathrm{Al} / \mathrm{Si}$ scattering single scattering (SS) paths in framework-interacting $\mathrm{Zn}^{2+}$ sites (see also the insets of Fig. 5b,c). This assignment is corroborated by EXAFS structural analysis reported below. The presence of aggregated $\mathrm{Zn}$ metal and $\mathrm{ZnO}$ nanoparticles cannot be reconciled with the overall XANES shape. The same conclusion is reached by the raw FT of the EXAFS spectra. Indeed, although Zn-metal and $\mathrm{ZnO}$ bulk compounds exhibit in the modulus of the FT a $\mathrm{Zn}-\mathrm{Zn}$ and $\mathrm{Zn}-\mathrm{O}-$ Zn component at ca. $2.3 \AA$ and $3.0 \AA$, respectively (Fig. 4b) the phases of such components are completely different from that present in the corresponding spectra of the Zn-ZSM-5 catalysts, as clearly appreciable in Fig. 4c. These considerations definitively 
rule out the presence of any significant contribution from well-defined $\mathrm{ZnO}$ or $\mathrm{Zn}$ metal nano-particles. Dealing with an 'average' technique, it is difficult, however, to conclude on the presence of very diluted dimeric $\mathrm{Zn}$ species.

Under MTA conditions, only slight modifications in the XAS spectra are observed compared to the activated catalysts. Interestingly, the XANES region shows clearer changes in the position and relative intensity of the $\mathbf{B}$ and $\mathbf{C}$ features (in Fig. 4a), whereas EXAFS remains almost unchanged. This could be consistent with interaction of $\mathrm{H}$ with framework-coordinated Zn-sites during the catalysis. After pretreatment and still during MTA, we observe the formation of a small shoulder in the rising-edge region at ca. 9660 $\mathrm{eV}$ (feature $\mathbf{X}$ ). As discussed in more details in the Supporting Information, (Fig. S4) feature $\mathrm{X}$ can be tentatively connected with the formation of atomic-like $\mathrm{Zn}^{0}$ species [70] or $\mathrm{Zn}^{+}-\mathrm{Zn}^{+}$dimers [65] in very low abundance ( $<10 \%$ total $\left.\mathrm{Zn}\right)$, although further studies are required to clarify its origin.
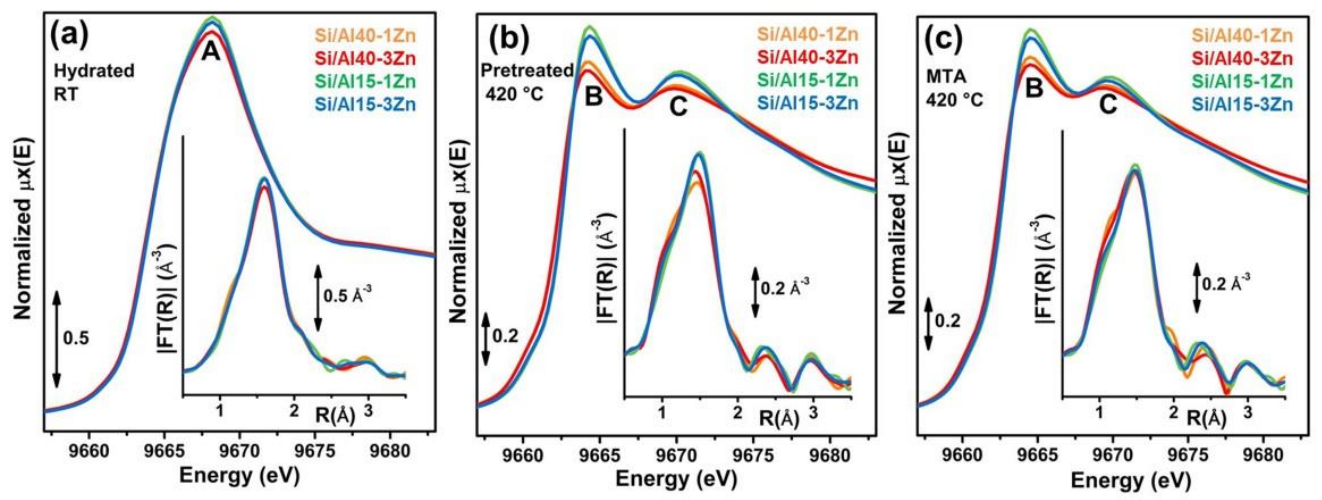

Fig. 5. Zn K-edge XANES (main panels) and FT-EXAFS spectra (insets) for Zn-ZSM-5 catalysts with different composition in term of $\mathrm{Si} / \mathrm{Al}$ in the parent zeolite and Zn-loading (from 0.7 to 1.9 wt\%) collected at key process steps: (a) hydrated catalysts at RT; (b) pretreated catalysts in air at $500{ }^{\circ} \mathrm{C}$ and cooled at $420^{\circ} \mathrm{C}$; (c) during MTA at $420{ }^{\circ} \mathrm{C}$. All the FT-EXAFS spectra have been obtained by transforming the $\mathrm{k}^{2} \chi(\mathrm{k})$ functions in the $2.5-12.5 \AA^{-1}$ range. 
Fig. 5 compares the Zn K-edge XAS spectra of selected Zn-ZSM-5 catalysts with different $\mathrm{Si} / \mathrm{Al}$ ratio of the parent zeolite and $\mathrm{Zn}$-loadings, in their hydrated state, after pretreatment, and in operando conditions during MTA. As anticipated, the XAS features observed at the different process steps shows only minor modifications as a function of the composition. In particular, in the hydrated state, all the catalysts show equivalent XANES and EXAFS spectra, hardly distinguishable from the $\mathrm{Zn}^{2+} / \mathrm{H}_{2} \mathrm{O}$ reference, as discussed above. Nevertheless, small but systematic differences can be appreciated in the XAS spectra of the pretreated catalysts. In particular, the intensity of the $\mathbf{B}$ and $\mathbf{C}$ features in the XANES appears to be significantly influenced by the Si/Al ratio: the catalysts with $\mathrm{Si} / \mathrm{Al}=15$ show higher intensity at both peaks with respect to Zn-ZSM-5 samples with $\mathrm{Si} / \mathrm{Al}=40$. A higher $\mathrm{Al}$ content in the framework seemingly also induces a small shift of the absorption edge to higher energy. In the FT-EXAFS, Si/Al = 15 samples exhibit a slight enhancement in the intensity of both first- and second-shell peaks with respect to the $\mathrm{Si} / \mathrm{Al}=40$ series, pointing out a small increase in the average coordination numbers of $\mathrm{Zn}$ centers as a function of the framework composition. In addition, the first-shell peak sharpens and slightly shifts to higher R-values. The impact of the Zn-loading appears less pronounced: high- and low-loading catalysts give almost equivalent XANES and EXAFS spectra, except for a small enhancement in the intensity of the $\mathbf{B}$ peak systematically observed in low-loading materials. Under MTA conditions, although the XAS spectra of the samples appears still organized in two groups according to the Si/Al ratio, the differences in the XANES and in the EXAFS region among $\mathrm{Si} / \mathrm{Al}=15$ and $\mathrm{Si} / \mathrm{Al}=40$ are even less pronounced.

Considering the relatively low $\mathrm{Al}$ density in all our samples, it is possible to envisage $\mathbf{Z}[\mathrm{Zn}(\mathrm{OH})]$ complexes as the dominant $\mathrm{Zn}$-species in the activated materials. To support 
this hypothesis and obtain detailed structural information about the major Zn-species formed in the catalysts after activation, DFT was employed to predict the local geometry of $\mathbf{Z}[\mathrm{Zn}(\mathrm{OH})]$ stabilized in the 5-membered ring (5R) of the ZSM-5 framework structure, previously proposed as the most favourable and accessible location for the $\mathrm{Zn}$ cations [71, 72]. The optimized geometry for the $\mathbf{Z}[\mathrm{Zn}(\mathrm{OH})]$ complex is depicted in Fig. 6: the metal centre adopts a highly distorted pseudo-tetrahedral coordination, protruding towards the large 10-membered ring $(10 \mathrm{R})$, with the $\left(\mathrm{OH}^{-}\right)$ligand pointing towards the centre of the 10R. As detailed in Fig. 6b, the $\mathrm{Zn}$ centre has four O neighbours in the first coordination shell, distributed over a rather broad distance range, from $1.78 \AA$ for the $\mathrm{O}_{\text {ef }}$ atom of the $\mathrm{OH}$ group, to ca. 1.90 and $2.40 \AA$ for the nearer $\mathrm{O}_{\mathrm{fw}}$ and the two $\mathrm{O}_{\mathrm{fw}}^{\prime}$ atoms further away. In the second-shell region, the DFT-model foresees an $\mathrm{Al}_{\text {fw }}$ at ca. $2.97 \AA$, while the remaining $\mathrm{Si}$ and $\mathrm{O}$ atoms of the 5R fall in the 3.14-3.40 $\AA$ range from the $\mathrm{Zn}$ centre.

We fitted the EXAFS spectrum of the pretreated Si/Al40-3Zn catalyst using the DFToptimized $\mathbf{Z}[\mathrm{Zn}(\mathrm{OH})]$ geometry as the initial guess for the structural parameters, while fixing the coordination numbers for each coordination shell to the DFT ones (see experimental section for details on the fitting model). Fig. 6c and 6d compare the experimental and best fit curves, together with the principal scattering contributions to the EXAFS signal, while the best fit values for the parameters optimized in the fit are reported in Table 4. Overall, the $\mathbf{Z}[\mathrm{Zn}(\mathrm{OH})]$ model allows a very good reproduction of the experimental spectrum, with physically reliable values for all the optimized parameters and Debye-Waller (DW) factors falling in the typical ranges expected for high-temperature data collection.

Table 4. Results from EXAFS fit for the Si/A140-3Zn activated catalyst (data collection temperature: $420^{\circ} \mathrm{C}$ ) using the DFT-optimized $\mathrm{Z}[\mathrm{Zn}(\mathrm{OH})]$ geometry shown in Fig. 6 . The fit was 
performed in R-space, in the range $\left(1.0\right.$ - 3.3) $\AA$, employing the k-range $(2.5-11.0) \AA^{-1}$ for the FT (number of independent point $\mathrm{N}_{\text {ind }}=2 \Delta \mathrm{k} \Delta \mathrm{R} / \pi>17$ ). Under round brackets, the DFT optimized distances are reported for comparison.

\begin{tabular}{|c|c|}
\hline EXAFS Parameters & Best fit values \\
\hline $\begin{array}{l}\text { R-factor } \\
\mathrm{N}_{\text {par }}\left(\mathrm{N}_{\text {ind }}\right) \\
\mathrm{S}_{0}^{2} \\
\Delta \mathrm{E}(\mathrm{eV})\end{array}$ & $\begin{array}{c}0.021 \\
11(17) \\
1.1 \pm 0.2 \\
-9 \pm 1 \\
\end{array}$ \\
\hline $\begin{array}{l}\mathrm{R}_{\mathrm{O}(\mathrm{ef})}(\AA) \\
\sigma_{\mathrm{O}(\mathrm{ef})}\left(\AA^{2}\right)\end{array}$ & $\begin{array}{c}1.83 \pm 0.04 \\
(1.78) \\
0.007 \pm 0.003\end{array}$ \\
\hline $\begin{array}{l}\mathrm{R}_{\mathrm{O}(\mathrm{fw})}(\AA) \\
\left\langle\mathrm{R}_{\mathrm{O}^{\prime}(\mathrm{fw})}\right\rangle(\AA) \\
\sigma_{\mathrm{O}(\mathrm{fw})}^{2}(\AA 2)\end{array}$ & $\begin{array}{c}1.90 \pm 0.05 \\
(1.90) \\
2.43 \pm 0.02 \\
(2.40) \\
0.006 \pm 0.003\end{array}$ \\
\hline $\begin{array}{l}\mathrm{R}_{\mathrm{T}(\mathrm{fw})}(\AA) \\
\sigma_{\mathrm{Al}(\mathrm{fw})}^{2}\left(\AA^{2}\right)\end{array}$ & $\begin{array}{c}2.96 \pm 0.07 \\
(2.97) \\
0.007 \pm 0.005\end{array}$ \\
\hline $\begin{array}{l}\alpha_{\mathrm{fw}^{\mathrm{a}}}{ }^{\mathrm{a}} \mathrm{SS}_{\mathrm{fw}}\left(\AA^{2}\right)^{\mathrm{a}} \\
\end{array}$ & $\begin{array}{c}0.01 \pm 0.01 \\
0.007 \pm 0.005\end{array}$ \\
\hline
\end{tabular}

${ }^{a} S S$ paths involving farer Si/O neighbors of the $5 R(f \boldsymbol{w})$, with distances from the Zn absorber in the 3.14-3.40 A range are modelled with a common contraction/expansion factor $\alpha_{f w}$ and $D W$ factor $\sigma_{\text {fw }}^{2}$ increasing as the square root of the distance $R_{\text {efffi } i}$ of the $i^{\text {th }}$ atom from the absorber $\left(\Delta R_{f w, i}=\alpha_{f w} R_{e f f, i}, \sigma_{f w, i}^{2}=s s_{f w}\left(R_{e f f ;} / R_{0}\right)^{1 / 2}\right.$, where $R_{0}$ is the shortest $R_{\text {eff }}$ for the group of paths $)$. See also experimental section for details.

These results support the presence of a major population of $\mathbf{Z}[\mathrm{Zn}(\mathrm{OH})]$ species at $\mathrm{Si} / \mathrm{Al}$ $=40$. The similarity of the FT-EXAFS in activated catalysts with different composition also suggests an important contribution of such $\mathrm{Zn}^{2+}$ moieties at $\mathrm{Si} / \mathrm{Al}=15$. In this respect, the higher density of $\mathrm{Al}$ in the framework is expected to result in a higher, although still limited, probability to have $5 \mathrm{Rs}$ with $2 A l$ sites, or two $1 A l$ sites in neighbouring $5 \mathrm{Rs}$. A correspondingly larger fraction of $2 A l \mathbf{Z}_{2} \mathrm{Zn}$ species can thus exist in these catalysts. Interestingly, a previous DFT-based analysis of such sites by Yakovlev et al. [71] evidenced a less distorted environment with respect to what we observe in the $\mathbf{Z}[\mathrm{Zn}(\mathrm{OH})]$ 
geometry described above, with the four first-shell $\mathrm{Zn}-\mathrm{O}_{\mathrm{fw}}$ distances in the $1.93-2.04 \AA$ range. A larger fraction of $\mathbf{Z}_{2} \mathbf{Z n}$ sites in such configuration would be in line with the slight intensity increase and sharpening observed in the first-shell peak of the FT-EXAFS spectra of activated Zn-ZSM-5 catalysts with $\mathrm{Si} / \mathrm{Al}=15$ (Fig. 5b).
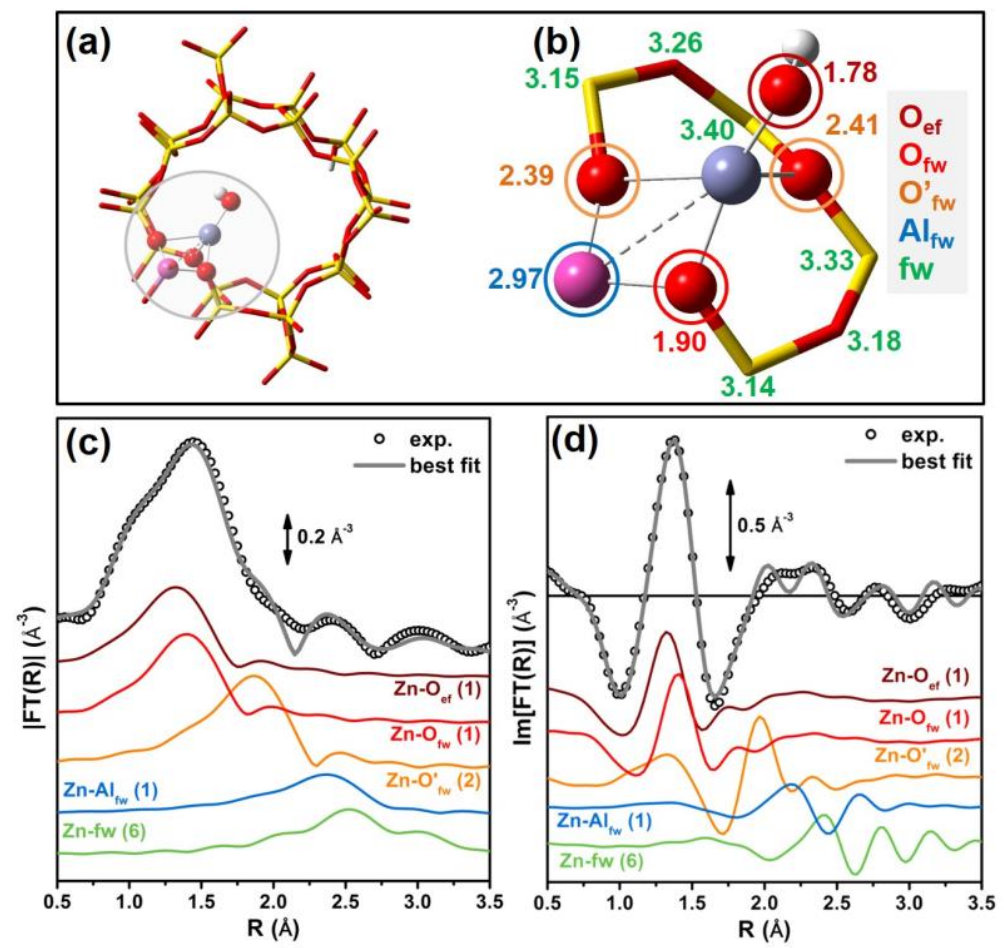

Fig. 6. (a) DFT-optimized geometry for the $\mathbf{Z}[\mathrm{Zn}(\mathrm{OH})]$ complex in the $5 \mathrm{R}$ of the ZSM-5 framework. (b) view of the full optimized cluster with the $\mathbf{Z}[\mathrm{Zn}(\mathrm{OH})]$ complex highlighted by a grey circle; magnified view of the $\mathrm{Zn}$ local environment in the $5 \mathrm{R}$, with coloured circles indicating the different coordination shells included in the EXAFS fit and DFT distances of each atom from the Zn absorber expressed in $\AA$. Atom colour code as follows: Zn, purple; H, white; O, red; Al, pink; Si, yellow. (c,d) Comparison between modulus (c) and imaginary part (d) of the experimental FT-EXAFS spectra (black circles) and corresponding best fit (solid grey lines) for $\mathrm{Si} / \mathrm{A} 140-3 Z \mathrm{Zn}$ pretreated catalyst (data collection temperature: $420^{\circ} \mathrm{C}$ ) using the DFT-optimized $\mathbf{Z}[\mathrm{Zn}(\mathrm{OH})]$ geometry shown in Fig. 6 . The principal contributions to the EXAFS signal are also shown, vertically translated for clarity; the values of the parameters optimized in the fits are reported in Table 4. 


\subsection{Catalytic testing results}

To evaluate the promoting effect of $\mathrm{Zn}$ as dehydrogenating agent and the synergy between $\mathrm{Zn}$ and Brønsted acid sites, all the described materials were tested as catalysts in the methanol to aromatics transformation at $400{ }^{\circ} \mathrm{C}$ at the conditions described in the experimental section. Under such conditions, all the samples reached full initial conversion of oxygenates (methanol and dimethyl ether) and the shape of the deactivation curves of the exchanged zeolites was similar to that of parent H-ZSM-5 (Fig. 7), with an initial period of complete conversion after which a rapid deactivation occurs leading to conversion values close to $0 \%$. Nonetheless, a clear correlation between lifetime and sample composition in terms of both $\mathrm{Al}$ and $\mathrm{Zn}$ content was observed. First of all, comparing samples without Zn, H-ZSM-5 with higher density of acid sites (Si/Al15-P) showed a shorter lifetime than the parent zeolite with $\mathrm{Si} / \mathrm{Al}=40$. On the other hand, for the samples prepared with the same parent zeolite and increasing $\mathrm{Zn}$ content, it is clear that the stability decreases with increasing Zn content for both series of samples (Fig. 7). The loss in stability caused by the incorporation of $\mathrm{Zn}$ or other transition metals have been observed before $[30,73]$ and, in our case since no other remarkable changes are observed in the physicochemical properties, can be initially attributed to the variations in the acidity of the materials. For the correct interpretation of this observation it should be taken into account that both the Brønsted and Lewis acid sites play important roles in the methanol transformation and catalyst deactivation. 


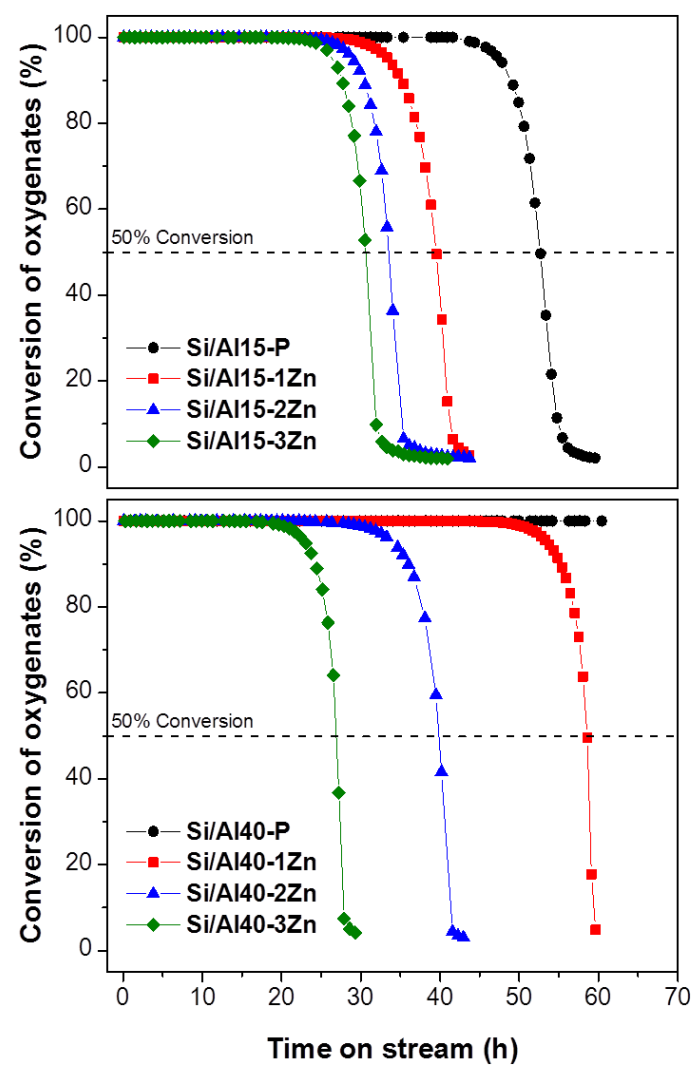

Fig. 7. Conversion of oxygenates (DME+MeOH) at $400{ }^{\circ} \mathrm{C}$ and WHSV $=3 \mathrm{~h}^{-1}$ vs time on stream over the parent and exchanged zeolites with the two selected $\mathrm{Si} / \mathrm{Al}$ ratios.

The resistance of the catalyst to deactivation can be quantified by calculating and comparing cumulative conversion capacities and the turnover number of each catalyst, described as the total weight of methanol converted per gram of catalysts or per accessible active center, respectively, until complete deactivation. Janssens has described deactivation as a loss in active catalyst mass with time, which may be perceived as a decrease in effective contact time [74]. Deactivation coefficients (a) and reaction rate contants (k), as described in Janssens' model, have been calculated for our samples and are collected, together with turnover numbers (TON) and conversion capacities, in Table 5. As expected from the time to the methanol breakthrough for the different catalysts in 
the deactivation curves, the deactivation coefficient is within each catalyst series higher for samples with higher $\mathrm{Zn}$ content. The deactivation coefficient is also higher for the $\mathrm{Si} / \mathrm{Al}=15$ parent sample relative to the $\mathrm{Si} / \mathrm{Al}=40$ parent sample. These observations are also manifested by the calculated values of the cumulative conversion capacity, which are higher for both parent samples and far higher in the case of the pure zeolite with $\mathrm{Si} / \mathrm{Al}=40$. Comparing the turnover number of the parent samples, Si/Al40-P has a clearly higher TON than Si/Al15-P, which means that each Brønsted site is converting more grams of methanol in the former. It is surprising, though, that the turnover number of the exchanged zeolites decreases for high $\mathrm{Zn}$ contents in the $\mathrm{Si} / \mathrm{Al}=40$ materials, whereas it is quite independent on the $\mathrm{Zn}$ content in the materials with $\mathrm{Si} / \mathrm{Al}=15$. Clearly, for the $\mathrm{Zn}$ containing catalysts, the Brønsted acid site density alone cannot alone describe the catalyst performance. This is also reflected by the reaction rate constants $(\mathrm{k})$. When these are normalized to Brønsted acid site density (Table 5), a quite profound increase is seen for the $\mathrm{Zn}$ containing catalysts in both series. A straightforward rationalization is that for the $\mathrm{Zn}$ containing catalysts, the Lewis acid sites introduced with the $\mathrm{Zn}$ contribute strongly to the catalytic activity, as one would also expect, based on the pronounced influence on both lifetime and selectivity. Beyond this, the relatively simple 2-parameter model of Janssens does not provide further, obvious insights.

Table 5. Cumulative conversion capacity, turnover number and calculated values of the deactivation coefficient and the constant rate of the zeolitic materials in MTA transformation at the experimental conditions tested.

\begin{tabular}{|c|c|c|c|c|}
\hline Sample & $\begin{array}{l}\text { Conversion } \\
\text { capacity* } \\
\left(\mathrm{gCH}_{3} \mathrm{OH} / \mathrm{gcat}\right)\end{array}$ & $\begin{array}{c}\text { Deactivation } \\
\text { coefficient } \ll a » \\
\left(\text { mg }_{\left.\text {cat } / \text { mol }_{\mathrm{CH}} \mathrm{OH}\right)}\right)^{* *}\end{array}$ & 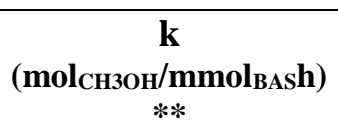 & $\begin{array}{l}\text { Turnover number } \\
\left(\mathrm{gCH}_{3} \mathrm{OH} / \mathrm{mmol}_{\mathrm{BAS})}\right)_{* *}\end{array}$ \\
\hline Si/Al15-P & 154 & 197 & 2.80 & 169 \\
\hline Si/Al15-1Zn & 116 & 263 & 6.43 & 429 \\
\hline Si/Al15-2Zn & 100 & 310 & 10.67 & 556 \\
\hline Si/Al15-3Zn & 91 & 341 & 10.29 & 455 \\
\hline
\end{tabular}




\begin{tabular}{lcccc}
\hline Si/Al40-P & 484 & 64 & 6.41 & 1564 \\
Si/Al40-1Zn & 173 & 177 & 13.57 & 721 \\
Si/Al40-2Zn & 116 & 261 & 10.47 & 644 \\
Si/Al40-3Zn & 79 & 388 & 12.25 & 464 \\
\hline
\end{tabular}

*Cumulative conversion capacity calculated as the total grams of methanol converted per gram of catalyst from 100 to $0 \%$ conversion.

** Deactivation coefficient (a) and rate constant (K) were calculated according to Janssens' model [74]. Rates are calculated per mmol of Brønsted acid site (BAS)

*** Turnover number considered as the total grams of methanol converted per mmol of Brønsted acid sites until full deactivation.

The product distribution was found to be influenced by the composition of the samples, both by the density of acid sites of the parent zeolite and by the presence of $\mathrm{Zn}$. Average selectivities to aromatics, collected in Table 6, were calculated at conversion levels between 100 and $50 \%$ in order to obtain a reliable measure not influenced by initial fluctuations in selectivities. Clearly, the presence of $\mathrm{Zn}$ in the catalysts has a promoting effect on the aromatics production (Table 6, Fig. 8). However, it must also be considered that when comparing parent samples, $\mathrm{Si} / \mathrm{A} 115-\mathrm{P}$ sample produces a considerably higher yield of aromatics, so, on a relative scale, the promoting effect of $\mathrm{Zn}$ is lower for the high Al sample (Table 6). For the parent samples, the differences found in yield of aromatics may be initially explained in terms of the greater density of available Brønsted and zeolite Lewis sites in SI/Al15-P sample which catalyze hydrogen transfer reactions leading to the formation of a higher amount of hydrogen rich molecules (such as alkanes). The goal of the incorporation of $\mathrm{Zn}$ is to avoid hydrogen transfer reactions and enhance dehydrogenation, thus producing aromatics together with molecular hydrogen instead of the mentioned alkanes. To evaluate to which extent aromatization is taking place via the dehydrogenation or hydrogen transfer mechanisms, the hydrogen transfer index (HTI) for 
C4 hydrocarbons was calculated (Fig. 8) [23]. A low HTI would mean that the aromatization is taking place mostly by dehydrogenation. As shown in the plot in Fig. 8, the higher the $\mathrm{Zn} / \mathrm{Al}$ ratio, the lower the HTI, despite the increasing yield of aromatics. Finally, the HTI is clearly higher in the Si/Al15 series of samples compared to samples with $\mathrm{Si} / \mathrm{Al}=40$.

Table 6. Average selectivity to aromatics calculated between 100 and $50 \%$ conversion for all the catalysts studied in MTA transformation at the experimental conditions described.

\begin{tabular}{lcccccc}
\hline \multicolumn{1}{c}{ Sample } & Benzene & Toluene & $\begin{array}{c}\mathbf{m} / \mathbf{p}- \\
\text { Xylene }\end{array}$ & $\begin{array}{c}\text { o- } \\
\text { Xylene }\end{array}$ & $\begin{array}{c}\text { Tri- } \\
\text { methylbenzenes }\end{array}$ & $\begin{array}{c}\text { Total } \\
\text { aromatics }\end{array}$ \\
\hline Si/Al15-P & 1 & 4 & 9 & 2 & 5 & 22 \\
Si/Al15-1Zn & 1 & 6 & 11 & 2 & 8 & 29 \\
Si/Al15-2Zn & 1 & 6 & 12 & 3 & 8 & 28 \\
Si/Al15-3Zn & 1 & 5 & 12 & 3 & 8 & 30 \\
\hline Si/Al40-P & 0 & 2 & 4 & 1 & 4 & 11 \\
Si/Al40-1Zn & 1 & 4 & 9 & 2 & 9 & 27 \\
Si/Al40-2Zn & 1 & 4 & 11 & 2 & 10 & 28 \\
Si/Al40-3Zn & 0 & 4 & 11 & 2 & 12 & 31 \\
\hline
\end{tabular}

Fig. 9 shows the yield of aromatics as a function of time on stream. For all the catalyst with $\mathrm{Si} / \mathrm{Al}=15$, the yield of aromatics starts at its maximum and decreases with time on stream. However, catalysts with $\mathrm{Si} / \mathrm{Al}=40$ have a rather different behavior, showing a gradual increase in the yield of aromatics with time on stream up to the methanol breakthrough.
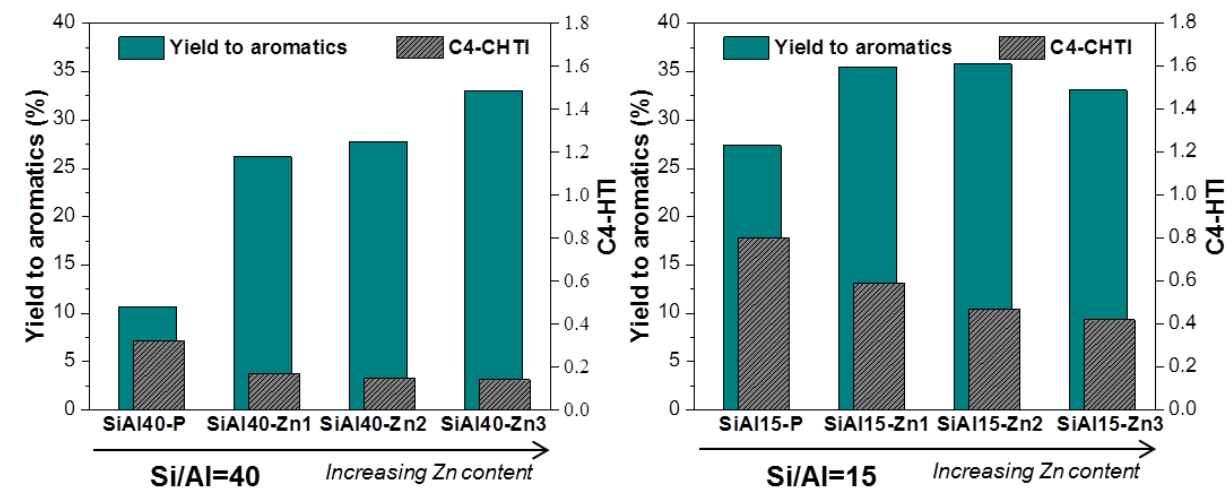
Fig. 8. Yield of aromatics and hydrogen transfer index after $4 \mathrm{~h}$ on stream over parent and exchanged samples.

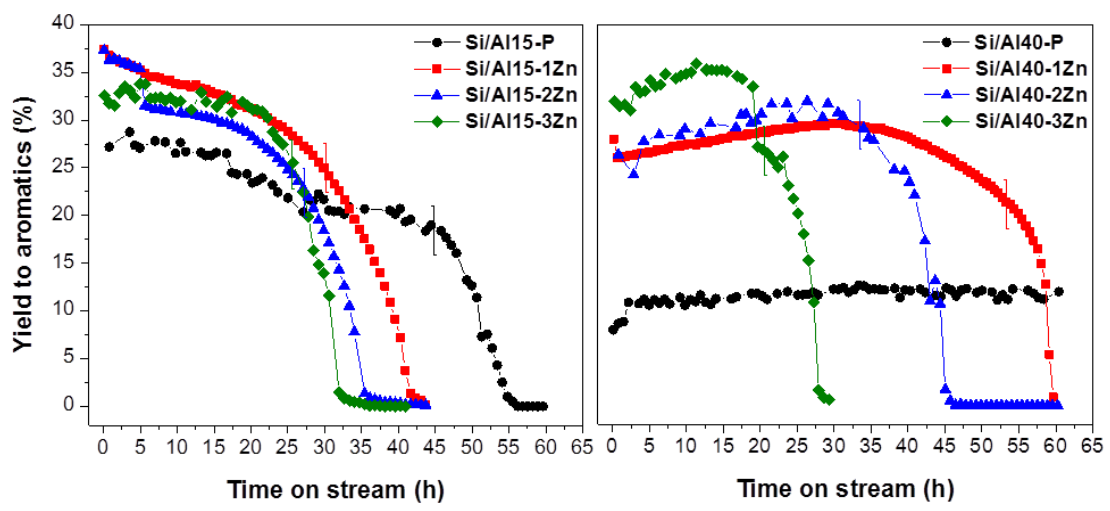

Fig. 9. Yield of aromatics as a function of time on stream using HZSM-5 and Zn-exchanged HZSM-5 materials as catalysts. Methanol breakthrough is marked with vertical lines for each catalyst.

To evaluate in detail how the product distribution evolves, the time evolution for the main reaction products $\left(\mathrm{C}_{3}, \mathrm{C}_{4}\right.$ and $\mathrm{C}_{6+}$ divided in aliphatic and aromatic compounds $)$ is presented in Fig. 10. The product distribution obtained is comparable with that reported previously for ZSM-5 catalysts in methanol to hydrocarbon conversion [75], and Si/Al40P sample is the only exception for which hydrocarbons with over 6 carbon atoms are not the main reaction products, and the catalysts produces predominantly $C_{3}$ and $C_{4}$ hydrocarbons instead. This can be explained considering that this material does not have a high density of active sites available for aromatization. Samples with $\mathrm{Si} / \mathrm{Al}=15$ show a gradual decrease in the yield of $\mathrm{C}_{6+}$ hydrocarbons with time on stream, and, for the $\mathrm{Zn}$ exchanged samples, the production of $\mathrm{C}_{3}$ molecules becomes gradually higher up to the time where methanol breakthrough occurs. 


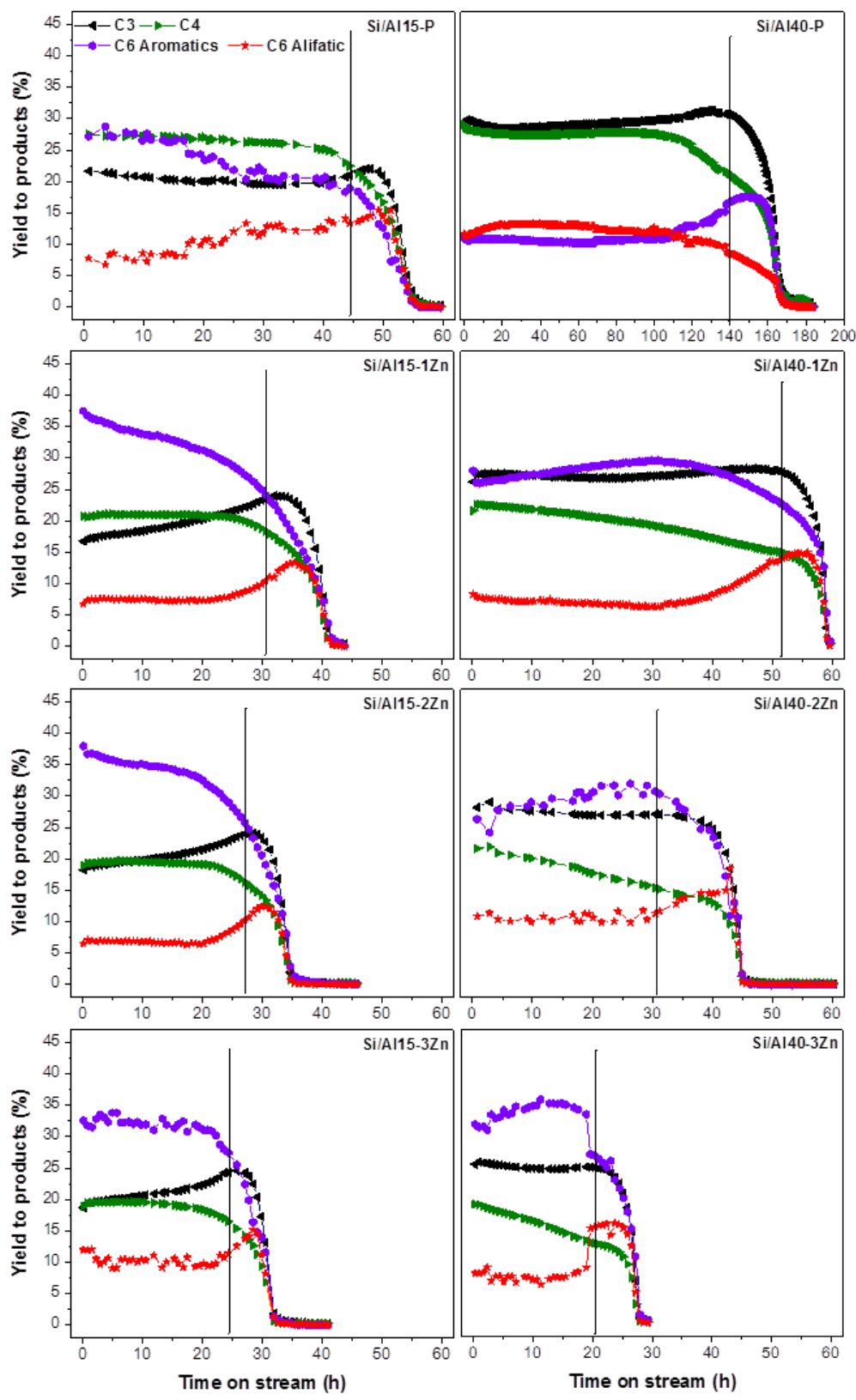

Fig. 10. Yield of hydrocarbon products vs of time on stream using HZSM-5 and Zn-exchanged HZSM-5 materials as catalysts. The same colour code is used in all the cases. Methanol breakthrough is marked with vertical lines.

\section{Discussion}

\subsection{Distribution and nature of reactive $\mathrm{Zn}$ sites.}


The type of $\mathrm{Zn}$ species that can be formed in zeolites and their role as active centers in the aromatization reaction are recurrent topics in the literature $[28,30,31,34,35,76]$. For example, it has been reported that ionic species inside the microporous structure such as $\mathrm{Zn}(\mathrm{OH})^{+}$are the responsible for the enhanced formation of aromatics rather than $\mathrm{ZnO}$ or metallic Zn agglomerates [28]. As described in Section 3.2, in this contribution we have used a wide range of techniques to characterize the $\mathrm{Zn}$ sites in MFI.

From the FTIR analysis with pyridine as probe molecule, it is clear that, in accordance with previous observations, the transition metal is incorporated at Brønsted sites in the zeolite, leading to a decrease in the density of Brønsted sites and the formation of new Lewis Zn sites (Fig. 2, Table 2). Considering the higher probability of forming Zn sites coordinating to two $\mathrm{Al}$ sites in an $\mathrm{Al}$ rich zeolite, it is not surprising that the decrease is more pronounced in the case of the parent material with $\mathrm{Si} / \mathrm{Al}=15$; but it should be pointed out that in both cases more Lewis acid sites are formed than Brønsted are consumed (Table 2). One reasonable explanation would be that two molecules of pyridine can interact with one $\mathrm{Zn}$ site. In fact, the observed increase in Lewis sites for samples with $\mathrm{Si} / \mathrm{Al}=40$ is even higher than two times the number of Brønsted sites consumed. This interesting observation has also been reported in the literature $[28,30]$, and seems to be more pronounced when $\mathrm{Zn}$ is incorporated into the sample by ion exchange as compared to other methods, such as impregnation, direct synthesis or physical mixing [28]. Also, on the basis of the results obtained upon $\mathrm{CO}$ adsorption, we can infer that the ion exchange caused the generation of EFAl sites, resulting in the formation of additional Lewis sites. In the case of samples with $\mathrm{Si} / \mathrm{Al}=40$, the decrease in Brønsted acid sites correlates quite well with the amount of $\mathrm{Zn}$ incorporated, meaning that one $\mathrm{Zn}$ is incorporated per Brønsted site (Table 3). However, in the samples with $\mathrm{Si} / \mathrm{Al}=15$, the reduction in Brønsted 
acidity is 2.4-3.4 times higher than the amount of $\mathrm{Zn}$ exchanged into the samples, which clearly indicates that the $\mathrm{Zn}$ interacts with more than one $\mathrm{Al}$ center. As pointed out in Section 3.3.2, although the differences between the XAS spectra of the pre-treated samples are small, these support the presence of a slightly higher fraction of $\mathbf{Z}_{2} \mathrm{Zn}^{2+}$ sites in the $\mathrm{Si} / \mathrm{Al}=15$ series.

Unlike other transition metals in zeolites, $\mathrm{Zn}$ is rather difficult to detect by spectroscopic means, but no significant contribution from Zn-Zn scattering was detected in EXAFS that could correspond to metallic $\mathrm{Zn}, \mathrm{ZnO}$ or $\mathrm{Zn}$ dimers. Therefore, these species are probably not formed in the material in substantial quantities. Thus, we can conclude that mainly monomeric $\mathrm{Zn}$ sites, predominantly in the form of $\mathbf{Z Z n}(\mathrm{OH})^{+}$species are expected to be present in the samples (Fig. 4).

\subsection{Catalytic performance trends and role of $\mathrm{Zn}$ on the catalytic behaviour of the samples}

We have observed that increasing amounts of $\mathrm{Zn}$ leads to significant variations in product distribution and life time of the catalysts. For both sample series the presence of $\mathrm{Zn}$ causes an increase in the aromatization activity of the catalysts (Fig. 8, Fig. 9). According to the decrease in the calculated hydrogen transfer indices of $\mathrm{C} 4$ compounds $\left(\mathrm{C}_{4}-\mathrm{HTI}\right)$ at increasing $\mathrm{Zn}$ content, it is quite clear that $\mathrm{Zn}$ promotes the dehydrogenation pathway.

On the other hand, there is a clear reduction in lifetime with increasing $\mathrm{Zn}$ content in the zeolites. This negative effect has been observed before $[73,77]$ and might simply be related to the higher probability of forming deactivating coke molecules from the increased content of aromatics in the micropores of the zeolite. In fact, the most stable catalyst is $\mathrm{Si} / \mathrm{Al} 40-\mathrm{P}$, which is the one that displays the lowest yield of aromatics, because 
it does not have $\mathrm{Zn}$ sites or high enough density of Brønsted or Lewis acid sites to enhance the aromatization. As mentioned above, the extra framework Lewis (observed with FTIR) sites formed after the ion exchange might also catalyze fast hydrogen transfer reactions leading to aromatics and oxygen containing coke species via formaldehyde [24] thus further promoting the deactivation. In summary, the faster deactivation of samples with same $\mathrm{Al}$ content but increasing $\mathrm{Zn}$ exchanged can be explained in terms of both the higher concentration of aromatics in this samples, and the higher number of Lewis sites. However, it should be pointed out that it is unknown at this point whether or not the Lewis sites generated by $\mathrm{Zn}$ display the same tendency for the detrimental formaldehyde formation as the 'regular' Lewis acid sites present in non-exchanged catalysts.

So, at this point it is quite clear that the catalytic behaviour of the samples is influenced not just by the presence (and amount) of $\mathrm{Zn}$ but also by the $\mathrm{Zn} / \mathrm{Al}$ ratio in each case. Frequently, the outstanding catalytic performance of bifunctional metal-zeolite systems is attributed to the synergic effect of different active sites, in this case, $\mathrm{Zn}$ sites and Brønsted sites. This active-site synergy, which is proposed to tune the properties of the active centers and considered to be caused by proximity and interaction, has been described in previous literature as the origin of the unique catalytic properties of metalcontaining zeolites [78-81]. In this section, however, it is important to highlight that it is not necessarily the synergy between the $\mathrm{Zn}$ sites and the zeolite protonic acid sites, but simply an optimum concentration of both sites controlling which of the two possible mechanistic pathways for the aromatization that is dominating in each case. This implies that the impact of a certain amount of $\mathrm{Zn}$ would be different depending on the density of Brønsted acid sites in any particular sample and it is, in fact, the content of $\mathrm{Al}$ and $\mathrm{Zn}$ combined which defines if the reaction is dominated by the $\mathrm{Zn}$ or the zeolite and whether 
or not the aromatization is taking place by dehydrogenation or hydrogen transfer reactions. In other words, the transformation will be directed by the $\mathrm{Zn}$ or by the zeolite sites depending on the concentration of both active sites, and the ratio between $\mathrm{Zn}$ content $\mathrm{Si} / \mathrm{Al}$ in the zeolite.

To illustrate this situation, it is useful to compare the parent samples, where Si/Al15-P produced a clearly higher yield of aromatics than Si/Al40-P in the same experimental conditions. Since the parent samples do not have any dehydrogenation sites, aromatics will be formed by hydrogen transfer reactions, resulting in a high yield of alkanes and, thus, in a high hydrogen transfer index value (Fig. 8). In addition to that, we observe that samples obtained from the same parent zeolite display a systematic increase in yield of aromatics with the gradual increase Zn content. Also in both series of samples the HTI decreases markedly when $\mathrm{Zn}$ is incorporated in the samples (Fig. 8), but all the $\mathrm{Zn}$ exchanged samples from the $\mathrm{Si} / \mathrm{Al}=40$ series have lower values of HTI than any of the $\mathrm{Zn}$-exchanged samples with $\mathrm{Si} / \mathrm{Al}=15$ at any yield of aromatics. Taking into account that the $\mathrm{Zn}$ content is in all the samples around $1-2 \%$, the first expectation would be that the effect of $\mathrm{Zn}$ in both materials would be same, but the marked difference in HTI indicates that the aromatization reaction mechanism is governed by the relation between the $\mathrm{Zn}$ content and the $\mathrm{Si} / \mathrm{Al}$ ratio. In materials in which it is less likely to find a $\mathrm{Zn}$ site than to find a zeolite acid site, the aromatization reaction takes place mainly through the traditional hydrogen transfer reaction as it happens in the parent samples. We may, therefore, conclude that it is the large $\mathrm{Si} / \mathrm{Al}$ ratio and therefore the higher $\mathrm{Zn} / \mathrm{Al}$ ratios that leads to the lower degree of hydrogen transfer in the Si/Al40 series. This becomes very obvious comparing samples $\mathrm{Si} / \mathrm{Al} 15-3 \mathrm{Zn}$ and $\mathrm{Si} / \mathrm{Al} 40-3 \mathrm{Zn}$ : the yield of aromatics 
for both catalysts is around 33\%, but the C4-HTI obtained with the first one is two times higher compared to the latter one (Fig.8).

To verify to which extent the presence of $\mathrm{Zn}$ in the materials drives the reaction through the dehydrogenation pathway, the hydrogen transfer indices as a function of the yield of aromatics are presented in Fig. 11. At any value of yield of aromatics the HTI is lower for samples with higher $\mathrm{Zn}$ content and it is in general lower for samples belonging to the series with $\mathrm{Si} / \mathrm{Al}=40$, what makes clear the great influence that the $\mathrm{Zn} / \mathrm{Al}$ has in the mechanism of the aromatization. Nonetheless, the hydrogen transfer index is not zero in any case, which means that even in the samples with high $\mathrm{Zn}$ content some alkanes are formed. These alkanes can result from hydrogen transfer reaction or hydrogenation of olefins. It can be hypothesized, then, that either the aromatization is not taking place only over the $\mathrm{Zn}$ sites or that there are some reaction steps involving hydrogen transfer that $\mathrm{Zn}$ sites are not able to catalyze by dehydrogenation.

At the same time, the incorporation of $\mathrm{Zn}$ by ion exchange entails a loss of Brønsted sites in the zeolitic framework, that are necessary to catalyze the formation of the hydrocarbons needed for the dehydrogenation reaction. Thus, the quantity of $\mathrm{Zn}$ introduced in the zeolite should be controlled maintaining an optimum ratio between $\mathrm{Zn}$ sites, that enhance the aromatization by dehydrogenation, and Brønsted sites which are responsible for the conversion of methanol into hydrocarbons. 

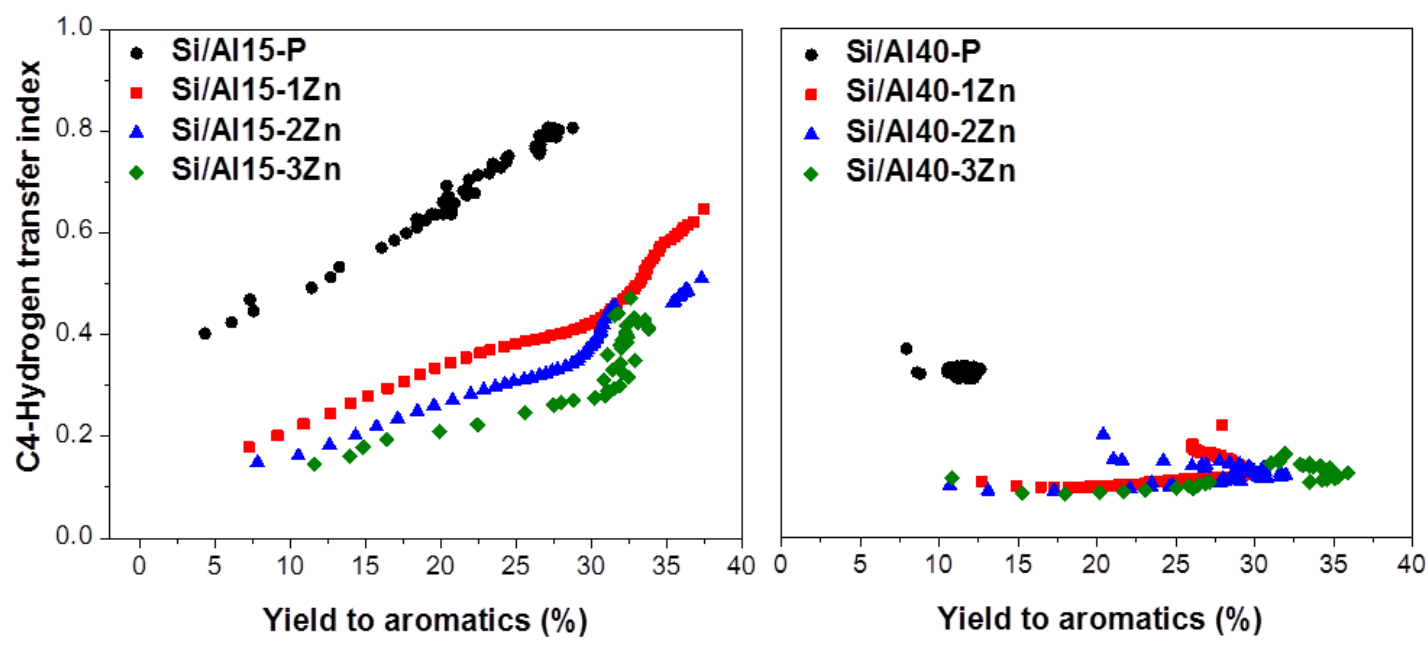

Fig. 11. Hydrogen transfer index for $\mathrm{C}_{4}$ hydrocarbons $\left(\mathrm{C}_{4}-\mathrm{HTI}\right)$ as a function of the yield of aromatics obtained in the reaction using HZSM-5 and Zn-HZSM-5 materials.

\subsection{Structure-reactivity relationships. Role of $\mathrm{Zn}$-sites in the MTA transformation.}

The fact that $\mathrm{Zn}$ and other transition metals are active as dehydrogenating agents in metalzeolite bifunctional catalysts is well known, but an exact mechanistic understanding is often missing. Generally, metal sites act polarizing on neighbouring molecular bonds, and $\mathrm{Zn}$ sites in particular show a certain affinity for hydrogen, which could accelerate the combination of surface hydrogen via dehydrogenation or dehydrocyclization [31, 82-84]. This capacity has been attributed to the presence of pairs of Lewis acid $\left(\mathrm{Zn}^{2+}\right)$ and basic $\left(\mathrm{O}^{2-}\right)$ species in $\mathrm{ZnO}$ material. Taking this into account, it can be hypothesized that the $\mathrm{Zn}-\mathrm{O}$ bond in the $\mathrm{Zn}$ species formed in the zeolites (primarily the $\mathbf{Z}[\mathrm{Zn}(\mathrm{OH})]$ complexes identified by XAS in the pretreated catalysts) can be comparable to those in $\mathrm{ZnO}$. Thus, it is plausible that the dehydrogenation starts with the interaction of hydrogen with the formed $\mathrm{Zn}$ species. These $\mathrm{Zn}$ species can be considered, then, as a vessel for the recombinative desorption of hydrogen as molecular $\mathrm{H}_{2}$ to happen. Noteworthy, in MTA conditions, only slight modifications in the XAS spectra are observed with respect to the 
activated catalysts. Interestingly, the XANES region shows clearer changes in the position and relative intensity of the two $\mathbf{B}$ and $\mathbf{C}$ peaks, whereas EXAFS remains almost unchanged (see Fig. 5). These evidences could be consistent with interaction of $\mathrm{H}$ with framework-coordinated Zn-sites during the catalysis. Indeed, it is known that XANES provides a highest sensitivity in such case, probing the perturbation in the electronic structure of the metal centre upon the formation of $\mathrm{H}$-adducts $[85,86]$, whereas the presence of $\mathrm{H}$ in the coordination sphere of $\mathrm{Zn}$ is poorly detectable by EXAFS due to its very low scattering amplitude.

As a summary, $\mathbf{Z Z n}(\mathrm{OH})^{+}$species in zeolites are most likely responsible for the dehydrogenation reactions that leads to aromatization. However, to be able to obtain an aromatics rich mixture of hydrocarbons, inhibiting the formation of undesired light alkane by-products it is necessary to control not just the $\mathrm{Zn}$ content in the zeolite but also the density of Brønsted sites of the zeolite. As discussed in the previous section, some Brønsted acidity is necessary to build olefins as precursors of the formation of aromatics, but if the density of Brønsted sites is too high, the reaction will be dominated by the regular zeolite sites and not the $\mathrm{Zn}$ sites, and the hydrogen transfer mechanism would be favoured.

\section{Conclusions}

The catalytic performance of bifunctional Zn-ZSM-5 catalysts was studied in the methanol to aromatics transformation. Zn-ZSM-5 samples were produced by ion exchanging two parent materials with $\mathrm{Si} / \mathrm{Al}=15$ and 40 up to three times, thus increasing the amount of $\mathrm{Zn}$ incorporated in the material. $\mathrm{Zn}$ speciation in the materials was also studied. Characterization results evidence that the dominant $\mathrm{Zn}$-species formed in the 
material are $\mathrm{Zn}(\mathrm{OH})^{+}$complexes and there is no evidence for the formation of large $\mathrm{ZnO}$ or metallic aggregates. $\mathrm{Zn}$ is incorporated in the structure mainly over the Brønsted sites, forming new Lewis sites and consuming Brønsted acid centers.

The presence of $\mathrm{Zn}$ in the catalyst clearly influences the catalytic performance of the samples in MTA both in terms of product selectivity and catalyst lifetime. With increasing $\mathrm{Zn}$ content, the yield of aromatics increases in comparison with the corresponding parent zeolite, but the catalyst lifetime progressively decreases. It is also clear from our data that the $\mathrm{Zn} / \mathrm{Al}$ ratio can be considered as a good descriptor of the aromatization activity. Comparing samples with similar $\mathrm{Zn}$ content, a higher density of acid sites (lower Si/Al ratio in the parent sample) favors the hydrogen transfer reactions, which translates into a higher yield of aromatics but also a higher production of alkanes. On the other hand, in samples with lower density of $\mathrm{Al}$ sites, the aromatization is governed by the $\mathrm{Zn}$ sites rather than by the zeolite acid centers and the aromatization takes place mainly by dehydrogenation, thus increasing the yield of aromatics while keeping the hydrogen transfer index and the production of alkanes low.

\section{Acknowledgements}

This work has been partially supported by the Innovation Fund Denmark (Ref. 519000019B). I. Pinilla-Herrero acknowledges this institution for the concession of an Industrial Postdoc contract. C. Lamberti acknowledges the Megagrant of the Russian Federation Government to support scientific research at the Southern Federal University, No. 14.Y26.31.0001. C. Atzori and C. Negri from Department of Chemistry (University of Turin) are gratefully acknowledged for infrared and XAS measurements.

\section{Supplementary Material}


Supplementary data associated with this article can be found in the online version.

\section{References}

[1] M. Bender, New Technologies and Alternative Feedstocks in Petrochemistry and Refining, Preprints of the DGMK, (2013), 59.

[2] E. Lalik, X. Liu, J. Klinowski, J. Phys. Chem., 96 (1992) 805.

[3] Y. Ono, K. Kanae, J. Chem. Soc., Faraday Trans., 87 (1991) 669.

[4] C.D. Chang, A.J. Silvestri, J. Catal., 47 (1977) 249.

[5] D. Xiang, Y. Qian, Y. Man, S. Yang, Appl. Energy, 113 (2014) 639.

[6] A.M. Niziolek, O. Onel, C.A. Floudas, AIChE J., 62 (2016) 1531.

[7] G.A. Olah, A. Goeppert, G.K.S. Prakash, J. Org. Chem., 74 (2009) 487.

[8] M. Martín, Engineering, 3 (2017) 166.

[9] U. Olsbye, M. Bjørgen, S. Svelle, K.-P. Lillerud, S. Kolboe, Catal. Today, 106 (2005) 108.

[10] S. Svelle, F. Joensen, J. Nerlov, U. Olsbye, K.-P. Lillerud, S. Kolboe, M. Bjørgen, J. Am. Chem. Soc., 128 (2006) 14770.

[11] M. Bjørgen, S. Svelle, F. Joensen, J. Nerlov, S. Kolboe, F. Bonino, L. Palumbo, S. Bordiga, U. Olsbye, J. Catal., 249 (2007) 195.

[12] T.V.W. Janssens, S. Svelle, U. Olsbye, J. Catal., 308 (2013) 122.

[13] M. Stöcker, J. Catal., 29 (1999) 3.

[14] A.G. Gayubo, A.T. Aguayo, A. Alonso, A. Atutxa, J. Bilbao, Catal. Today, 106 (2005) 112.

[15] D. Rojo-Gama, M. Signorile, F. Bonino, S. Bordiga, U. Olsbye, K.P. Lillerud, P. Beato, S. Svelle, J. Catal., 351 (2017) 33.

[16] I. Pinilla-Herrero, U. Olsbye, C. Márquez-Álvarez, E. Sastre, J. Catal., 352 (2017) 191.

[17] J.S. Martinez-Espin, M. Morten, T.V.W. Janssens, S. Svelle, P. Beato, U. Olsbye, Catal. Sci. Technol., 7 (2017) 2700.

[18] H. Schulz, Catal. Today, 154 (2010) 183.

[19] S. Müller, Y. Liu, M. Vishnuvarthan, X. Sun, A.C. van Veen, G.L. Haller, M.

Sanchez-Sanchez, J.A. Lercher, J. Catal.,325 (2015) 48.

[20] U. Olsbye, S. Svelle, K.P. Lillerud, Z.H. Wei, Y.Y. Chen, J.F. Li, J.G. Wang, W.B.

Fan, Chem. Soc. Rev., 44 (2015) 7155.

[21] A. Galadima, O. Muraza, Ind. Eng. Chem. Res., 54 (2015) 4891.

[22] U. Olsbye, S. Svelle, M. Bjørgen, P. Beato, T.V.W. Janssens, F. Joensen, S.

Bordiga, K.P. Lillerud, Angew. Chem. Int. Ed., 51 (2012) 5810.

[23] S. Ilias, A. Bhan, ACS Catal., 3 (2013) 18.

[24] S. Müller, Y. Liu, F.M. Kirchberger, M. Tonigold, M. Sanchez-Sanchez, J.A.

Lercher, J. Am. Chem. Soc., 138 (2016) 15994.

[25] C. Song, K. Liu, D. Zhang, S. Liu, X. Li, S. Xie, L. Xu, Appl. Catal., A, 470 (2014) 15.

[26] M. Conte, J.A. Lopez-Sanchez, Q. He, D.J. Morgan, Y. Ryabenkova, J.K. Bartley, A.F. Carley, S.H. Taylor, C.J. Kiely, K. Khalid, G.J. Hutchings, Catal. Sci. Technol., 2 (2012) 105.

[27] R. Barthos, T. Bánsági, T. Süli Zakar, F. Solymosi, J. Catal., 247 (2007) 368. 
[28] X. Niu, J. Gao, Q. Miao, M. Dong, G. Wang, W. Fan, Z. Qin, J. Wang, Microporous Mesoporous Mater., 197 (2014) 252.

[29] T. Gong, L. Qin, J. Lu, H. Feng, Phys. Chem. Chem. Phys., 18 (2016) 601.

[30] X. Niu, J. Gao, K. Wang, Q. Miao, M. Dong, G. Wang, W. Fan, Z. Qin, J. Wang, Fuel Process. Technol., 157 (2017) 99.

[31] J.A. Biscardi, G.D. Meitzner, E. Iglesia, J. Catal., 179 (1998) 192.

[32] J. Zhang, W. Qian, C. Kong, F. Wei, ACS Catal., 5 (2015) 2982.

[33] G. Qi, J. Xu, J. Su, J. Chen, X. Wang, F. Deng, J. Am. Chem. Soc., 135 (2013) 6762.

[34] H. Berndt, G. Lietz, J. Völter, Appl. Catal., A, 146 (1996) 365.

[35] H. Berndt, G. Lietz, B. Lücke, J. Völter, Appl. Catal., A, 146 (1996) 351.

[36] A.A. Gabrienko, S.S. Arzumanov, A.V. Toktarev, I.G. Danilova, I.P. Prosvirin, V.V. Kriventsov, V.I. Zaikovskii, D. Freude, A.G. Stepanov, ACS Catal., 7 (2017) 1818.

[37] S. Bordiga, C. Lamberti, F. Bonino, A. Travert, F. Thibault-Starzyk, Chem. Soc.

Rev., 44 (2015) 7262.

[38] S. Bordiga, E. Groppo, G. Agostini, J.A. van Bokhoven, C. Lamberti, Chem. Rev., 113 (2013) 1736.

[39] K.K. Matthias Thommes, Alexander V. Neimark, James P. Olivier, Francisco Rodriguez-Reinoso, Jean Rouquerol and Kenneth S. W. Sing, Pure Appl. Chem., 87 (2015) 1051.

[40] B.C. Lippens, J.H. de Boer, J. Catal., 4 (1965) 319.

[41] E. Selli, L. Forni, Microporous Mesoporous Mater., 31 (1999) 129.

[42] O. Mathon, A. Beteva, J. Borrel, D. Bugnazet, S. Gatla, R. Hino, I. Kantor, T.

Mairs, M. Munoz, S. Pasternak, F. Perrin, S. Pascarelli, J. Synchrotron Radiat, 22

(2015) 1548.

[43] D. Bellet, B. Gorges, A. Dallery, P. Bernard, E. Pereiro, J. Baruchel, J. Appl. Crystallogr., 36 (2003) 366.

[44] C. Lamberti, S. Bordiga, F. Bonino, C. Prestipino, G. Berlier, L. Capello, F. D'Acapito, F. Xamena, A. Zecchina, Phys. Chem. Chem. Phys., 5 (2003) 4502. [45] C. Lamberti, S. Bordiga, D. Arduino, A. Zecchina, F. Geobaldo, G. Spanó, F. Genoni, G. Petrini, A. Carati, F. Villain, G. Vlaic, J. Phys. Chem. B, 102 (1998) 6382. [46] B. Ravel, M. Newville, J. Synchrotron Radiat, 12 (2005) 537.

[47] A. Martini, E. Borfecchia, K.A. Lomachenko, I.A. Pankin, C. Negri, G. Berlier, P. Beato, H. Falsig, S. Bordiga, C. Lamberti, Chem. Sci., 8 (2017) 6836.

[48] E. Borfecchia, K.A. Lomachenko, F. Giordanino, H. Falsig, P. Beato, A.V.

Soldatov, S. Bordiga, C. Lamberti, Chem. Sci., 6 (2015) 548.

[49] Ch. Baerlocher, L.B. McCusker, Database of Zeolite Structures: <http://www. izastructure.org/databases/>.

[50] G. te Velde, F.M. Bickelhaupt, E.J. Baerends, C. Fonseca Guerra, S.J.A. van Gisbergen, J.G. Snijders, T. Ziegler, J. Comput. Chem., 22 (2001) 931.

[51] E. Van Lenthe, E.J. Baerends, J. Comput. Chem., 24 (2003) 1142.

[52] J.P. Perdew, K. Burke, M. Ernzerhof, Phys. Rev. Lett., 77 (1996) 3865.

[53] E.v. Lenthe, A. Ehlers, E.-J. Baerends, J. Chem. Phys., 110 (1999) 8943.

[54] H. Lermer, M. Draeger, J. Steffen, K.K. Unger, Zeolites, 5 (1985) 131.

[55] S.I. Zabinsky, J.J. Rehr, A. Ankudinov, R.C. Albers, M.J. Eller, Phys. Rev. B, 52 (1995) 2995.

[56] J.J. Rehr, R.C. Albers, Rev. Mod. Phys., 72 (2000) 621. 
[57] D.K. Pappas, E. Borfecchia, M. Dyballa, I.A. Pankin, K.A. Lomachenko, A. Martini, M. Signorile, S. Teketel, B. Arstad, G. Berlier, C. Lamberti, S. Bordiga, U. Olsbye, K.P. Lillerud, S. Svelle, P. Beato, J. Am. Chem. Soc., 139 (2017) 14961. [58] F. Bonino, S. Chavan, J.G. Vitillo, E. Groppo, G. Agostini, C. Lamberti, P.D.C. Dietzel, C. Prestipino, S. Bordiga, Chem. Mater., 20 (2008) 4957.

[59] P. Sazama, B. Wichterlova, J. Dedecek, Z. Tvaruzkova, Z. Musilova, L. Palumbo, S. Sklenak, O. Gonsiorova, Microporous Mesoporous Mater., 143 (2011) 87.

[60] M.B. Sayed, R.A. Kydd, R.P. Cooney, J. Catal., 88 (1984) 137.

[61] B. Onida, F. Geobaldo, F. Testa, F. Crea, E. Garrone, Microporous Mesoporous Mater., 30 (1999) 119.

[62] V.B. Kazansky, V.Y. Borovkov, A.I. Serikh, R.A. van Santen, B.G. Anderson, Catal. Lett., 66 (2000) 39.

[63] P. D'Angelo, M. Benfatto, S. Della Longa, N.V. Pavel, Phys. Rev. B, 66 (2002).

[64] J.E. Penner-Hahn, Coord. Chem. Rev., 249 (2005) 161.

[65] A. Oda, T. Ohkubo, T. Yumura, H. Kobayashi, Y. Kuroda, Dalton Trans., 44 (2015) 10038.

[66] S.M.T. Almutairi, B. Mezari, P. Magusin, E.A. Pidko, E.J.M. Hensen, ACS Catal., 2 (2012) 71.

[67] V. Yachandra, L. Powers, T.G. Spiro, J. Am. Chem. Soc., 105 (1983) 6596.

[68] K. Peariso, Z.H.S. Zhou, A.E. Smith, R.G. Matthews, J.E. Penner-Hahn, Biochemistry, 40 (2001) 987.

[69] K. Clark-Baldwin, D.L. Tierney, N. Govindaswamy, E.S. Gruff, C. Kim, J. Berg, S.A. Koch, J.E. Penner-Hahn, J. Am. Chem. Soc., 120 (1998) 8401.

[70] A. Oda, H. Torigoe, A. Itadani, T. Ohkubo, T. Yumura, H. Kobayashi, Y. Kuroda, Angew. Chem. Int. Ed., 51 (2012) 7719.

[71] A.L. Yakovlev, A.A. Shubin, G.M. Zhidomirov, R.A. van Santen, Catal. Lett., 70 (2000) 175.

[72] E.A. Pidko, R.A. van Santen, J. Phys. Chem. C, 111 (2007) 2643.

[73] Y. Xin, P. Qi, X. Duan, H. Lin, Y. Yuan, Catal. Lett., 143 (2013) 798.

[74] T.V.W. Janssens, J. Catal., 264 (2009) 130.

[75] M. Bjørgen, F. Joensen, M. Spangsberg Holm, U. Olsbye, K.-P. Lillerud, S. Svelle, Appl. Catal., A, 345 (2008) 43.

[76] A.L. Yakovlev, A.A. Shubin, G.M. Zhidomirov, R.A. van Santen, Catal. Lett., 70 (2000) 175.

[77] Y. Ni, A. Sun, X. Wu, G. Hai, J. Hu, T. Li, G. Li, Microporous Mesoporous

Mater., 143 (2011) 435.

[78] P. Meriaudeau, C. Naccache, J. Mol. Catal., 59 (1990) L31.

[79] A.G. Stepanov, S.S. Arzumanov, A.A. Gabrienko, V.N. Parmon, I.I. Ivanova, D. Freude, ChemPhysChem, 9 (2008) 2559.

[80] G. Qi, Q. Wang, J. Xu, J. Trébosc, O. Lafon, C. Wang, J.-P. Amoureux, F. Deng, Angew. Chem. Int. Ed., 55 (2016) 15826.

[81] G. Buckles, G.J. Hutchings, C.D. Williams, Catal. Lett., 11 (1991) 89.

[82] L.M. Lubango, M.S. Scurrell, Appl. Catal., A, 235 (2002) 265.

[83] C. Lamberti, A. Zecchina, E. Groppo, S. Bordiga, Chem. Soc. Rev., 39 (2010) 4951.

[84] D. Scarano, S. Bertarione, G. Spoto, A. Zecchina, C. Otero Areán, Thin Solid Films, 400 (2001) 50. 
[85] A.L. Bugaev, A.A. Guda, A. Lazzarini, K.A. Lomachenko, E. Groppo, R. Pellegrini, A. Piovano, H. Emerich, A.V. Soldatov, L.A. Bugaev, V.P. Dmitriev, J.A. van Bokhoven, C. Lamberti, Catal. Today283 (2017) 119.

[86] A.L. Bugaev, A.A. Guda, K.A. Lomachenko, V.V. Srabionyan, L.A. Bugaev, A.V. Soldatov, C. Lamberti, V.P. Dmitriev, J.A. van Bokhoven, J. Phys. Chem. C, 118 (2014) 10416.

\section{TABLE CAPTIONS}

Table 1. Experimental details of the Zn incorporation in two parent ZSM-5 zeolites with different $\mathrm{Si} / \mathrm{Al}$ ratios.

Table 2. Elemental composition of the samples measured by ICP and density of acid sites detected from the FTIR experiments using pyridine as probe molecule.

Table 3. Adsorption capacity and textural properties of the parent and $\mathrm{Zn}$-exchanged ZSM-5 samples*.

Table 4. Results from EXAFS fit for the Si/Al40-3Zn activated catalyst (data collection temperature: $420{ }^{\circ} \mathrm{C}$ ) using the DFT-optimized $\mathrm{Z}[\mathrm{Zn}(\mathrm{OH})]$ geometry shown in Fig. 6. The fit was performed in R-space, in the range $(1.0-3.3) \AA$, employing the k-range $(2.5$ - 11.0) $\AA^{-1}$ for the FT (number of independent point $\mathrm{N}_{\text {ind }}=2 \Delta \mathrm{k} \Delta \mathrm{R} / \pi>17$ ). Under round brackets, the DFT optimized distances are reported for comparison.

Table 5. Cumulative conversion capacity, turnover number and calculated values of the deactivation coefficient and the constant rate of the zeolitic materials in MTA transformation at the experimental conditions tested.

Table 6. Average selectivity to aromatics calculated between 100 and $50 \%$ conversion for all the catalysts studied in MTA transformation at the experimental conditions described.

\section{FIGURE CAPTIONS}

Fig. 1. Powder X-ray diffraction patterns of the parent H-ZSM-5 and the Zn-containing HZSM-5 zeolites. 
Fig. 2. FTIR spectra of the parent H-ZSM-5 and the Zn-containing HZSM-5 zeolites. a) FTIR spectra of the pre-treated samples in the $\mathrm{OH}$ stretching region. b) FTIR spectra of pyridine adsorbed on the zeolites.

Fig. 3. Background-subtracted FTIR spectra of CO (0.1 mbar) adsorbed at $-196{ }^{\circ} \mathrm{C}$ on parent H-ZSM-5 and Zn-containing HZSM-5 zeolites.

Fig. 4. Typical XAS fingerprints of Zn sites in Zn-ZSM-5 at key process steps. (a) Zn Kedge XANES for a representative Zn-ZSM-5 sample (Si/Al40-3Zn) in the hydrated state at RT, after pretreatment in air at $500{ }^{\circ} \mathrm{C}$ and cooling to $420{ }^{\circ} \mathrm{C}$ and during MTA at the same temperature. For comparison, the XANES spectra for a series of reference compounds (measured at RT) are also reported, i.e. $\mathrm{Zn}\left(\mathrm{NO}_{3}{ }^{-}\right)_{2}$ aqueous solution, representative of fully hydrated $\mathrm{Zn}^{2+}$ ions, $\mathrm{Zn}$ metal foil and $\mathrm{ZnO}$. (b, c) Magnitude (b) and imaginary part (c) of the FT-EXAFS spectra for the same sample and reference compounds reported in part (a), using the same colour code. All the FT-EXAFS spectra have been obtained by transforming the $\mathrm{k}^{2} \chi(\mathrm{k})$ EXAFS functions in the 2.5-12.5 $\AA^{-1}$ range.

Fig. 5. Zn K-edge XANES (main panels) and FT-EXAFS spectra (insets) for Zn-ZSM-5 catalysts with different composition in term of $\mathrm{Si} / \mathrm{Al}$ in the parent zeolite and $\mathrm{Zn}$-loading (from 0.7 to $1.9 \mathrm{wt} \%$ ) collected at key process steps: (a) hydrated catalysts at RT; (b) pretreated catalysts in air at $500{ }^{\circ} \mathrm{C}$ and cooled at $420{ }^{\circ} \mathrm{C}$; (c) during MTA at $420{ }^{\circ} \mathrm{C}$. All the FT-EXAFS spectra have been obtained by transforming the $\mathrm{k}^{2} \chi(\mathrm{k})$ functions in the 2.5-12.5 $\AA^{-1}$ range.

Fig. 6. (a) DFT-optimized geometry for the $\mathbf{Z}[\mathrm{Zn}(\mathrm{OH})]$ complex in the $5 \mathrm{R}$ of the ZSM-5 framework. (b) view of the full optimized cluster with the $\mathbf{Z}[\mathrm{Zn}(\mathrm{OH})]$ complex highlighted by a grey circle; magnified view of the $\mathrm{Zn}$ local environment in the 5R, with coloured circles indicating the different coordination shells included in the EXAFS fit and DFT distances of each atom from the $\mathrm{Zn}$ absorber expressed in $\AA$. Atom colour code as follows: $\mathrm{Zn}$, purple; H, white; O, red; Al, pink; Si, yellow. (c,d) Comparison between modulus (c) and imaginary part (d) of the experimental FT-EXAFS spectra (black circles) and corresponding best fit (solid grey lines) for Si/Al40-3Zn pretreated catalyst (data collection temperature: $420^{\circ} \mathrm{C}$ ) using the DFT-optimized $\mathbf{Z}[\mathrm{Zn}(\mathrm{OH})]$ geometry shown in Fig. 6. The principal contributions to the EXAFS signal are also shown, vertically 
translated for clarity; the values of the parameters optimized in the fits are reported in Table 4.

Fig. 7. Conversion of oxygenates (DME+MeOH) at $400{ }^{\circ} \mathrm{C}$ and $\mathrm{WHSV}=3 \mathrm{~h}^{-1}$ vs time on stream over the parent and exchanged zeolites with the two selected $\mathrm{Si} / \mathrm{Al}$ ratios.

Fig. 8. Yield of aromatics and hydrogen transfer index after $4 \mathrm{~h}$ on stream over parent and exchanged samples.

Fig. 9. Yield of aromatics as a function of time on stream using HZSM-5 and Znexchanged HZSM-5 materials as catalysts. Methanol breakthrough is marked with vertical lines for each catalyst.

Fig. 10. Yield of hydrocarbon products vs of time on stream using HZSM-5 and Znexchanged HZSM-5 materials as catalysts. The same colour code is used in all the cases. Methanol breakthrough is marked with vertical lines.

Fig. 11. Hydrogen transfer index for $\mathrm{C}_{4}$ hydrocarbons $\left(\mathrm{C}_{4}-\mathrm{HTI}\right)$ as a function of the yield of aromatics obtained in the reaction using HZSM-5 and Zn-HZSM-5 materials. 